\title{
Biosimilars - status in July 2020 in 16 countries
}

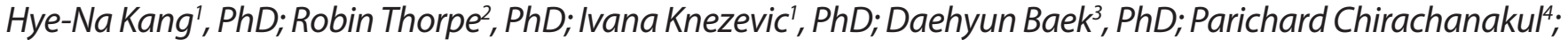 \\ Hui Ming Chua ; Dina Dalili, ${ }^{6}$ PhD; Freddie Foo ${ }^{7}, \mathrm{MSc}$; Kai Gao ${ }^{8}$, PhD; Suna Habahbeh ${ }^{9}$, PhD; Hugo Hamel ${ }^{10}$, PhD; \\ Edwin Nkansah" ${ }^{11}$, PhD; Maria Savkina ${ }^{12}$, PhD; Oleh Semeniuk ${ }^{13}$; Shraddha Srivastava ${ }^{14}$; João Tavares Neto ${ }^{15}$, PhD; \\ Meenu Wadhwa ${ }^{16}$, PhD; Teruhide Yamaguchi ${ }^{17}, \mathrm{PhD}$
}

\begin{abstract}
The World Health Organization (WHO) has provided specific guidance for biosimilar products to assist regulators, manufacturers and other professionals involved in the development and evaluation of these products. The development and approval of biosimilars are important for health care, as they allow the marketing of safe, efficacious and affordable biological products. Since the first biosimilars were approved in the EU in 2006, a series of biosimilars have been approved in many countries/geographical regions. This manuscript provides the figures on the status of approved biosimilars in 16 countries based on the information from regulatory experts and from publicly available data. It is clear that increasing numbers of biosimilars are now available in many countries and provide more options for treatments. It is expected that adoption of biosimilars will allow affordable health care and greater patient access to important medicinal products. It will also contribute to the overall WHO goal recognized by the World Health Assembly in 2014 by adopting a resolution on access to biotherapeutic products including biosimilars and on ensuring their quality, safety and efficacy.
\end{abstract}

Keywords: Approval, biosimilar, survey, WHO

\section{Introduction}

Development of biosimilars is important for health care as it allows the marketing of safe, efficacious and affordable biological products. The European Medicines Agency (EMA) was the first regulatory agency to establish a process for the approval of biosimilars and approved the first biosimilars in 2006.

Since then, there has been much progress in establishing the regulatory pathway for biosimilars and a wide range of biosimilars have been approved for marketing in many countries/ geographical regions [1]. An extensive number of biosimilars are now being used globally and are contributing considerably to widening patient access to appropriate biological medicines at reduced costs.

The World Health Organization (WHO) has taken a lead in the biosimilar field at the global level and has developed specific guidance for biosimilar development and approval as well as a number of other pertinent guidelines [2-4]. WHO has also organized a number of implementation workshops to assist regional regulatory agencies and manufacturers in the biosimilars area. As part of these workshops, surveys have been conducted to understand the current situation with biosimilars in the participants' countries $[1,5,6]$. These surveys provide a unique opportunity to establish the situation with currently marketed biosimilars/similar biotherapeutic products in 16 countries. This publication presents this information.

\section{Methods}

The survey was conducted as previously described [1], but the information was updated and confirmed in July 2020. The information contained in this survey report is from participants of 15 countries who agreed for their information to be disclosed. The feedback from the UK refers to the situation in the
European Union (EU) rather than specifically for the UK. Information from the US was not derived from the survey, but from the website of the US Food and Drug Administration (FDA). It should be noted that biological products in Table 1 have been approved as biosimilars in the countries as surveyed, but biosimilars approved in certain countries might not have been approved following a strict comparative regulatory process as recommended by WHO guidelines. The term 'approval' used in the manuscript is referring to the approval by the national regulatory authority. WHO did not conduct assessment of these products nor of the procedure for regulatory evaluation conducted by the national regulatory authorities as a basis for the 'approval'.

\section{Results}

Table 1 shows a breakdown of information received which includes country participating (in survey), International Nonproprietary Name (INN), brand name and manufacturer/ company name of product, the location of the producer of the product, the clinical indications approved, the reference product used and its manufacturer and the date the biosimilar/ similar biotherapeutic products was approved. Table 2 shows the numbers of biosimilars/similar biotherapeutic products approved by regulatory authorities in the 16 countries (updated July 2020) specified by product type.

\section{Discussion/Conclusions}

Following the EU's lead after their first biosimilar approvals in 2006, other countries have approved biosimilars/similar biotherapeutic products not only with increasing numbers but also with expanding the available product classes. 'Big pharma', e.g. in the EU and the US, continues to dominate the biosimilar market, but local manufacturers have played a significant role in producing biosimilars/similar biotherapeutic products in some countries, e.g. in China, India, Iran, Japan, Republic of Korea.

\section{Author for correspondence: Hye-Na Kang, PhD, World Health Organization, Department of Health Product Policy and Standards, 20 Avenue Appia,} CH-1211 Geneva, Switzerland

Submitted: 12 October 2020; Revised: 25 November 2020; Accepted: 25 November 2020; Published online first: 14 December 2020 
Table 1: Similar biotherapeutic products/biosimilars approved in 16 countries

The information below provided based on the categorization of similar biotherapeutic products/biosimilars by each national regulatory authority. Thus, similar biotherapeutic products/biosimilars approved in certain countries might not have been approved following as strict a regulatory process as is required by WHO guidelines. Indications also as reported by survey participants; not necessarily representing WHO approval of these.

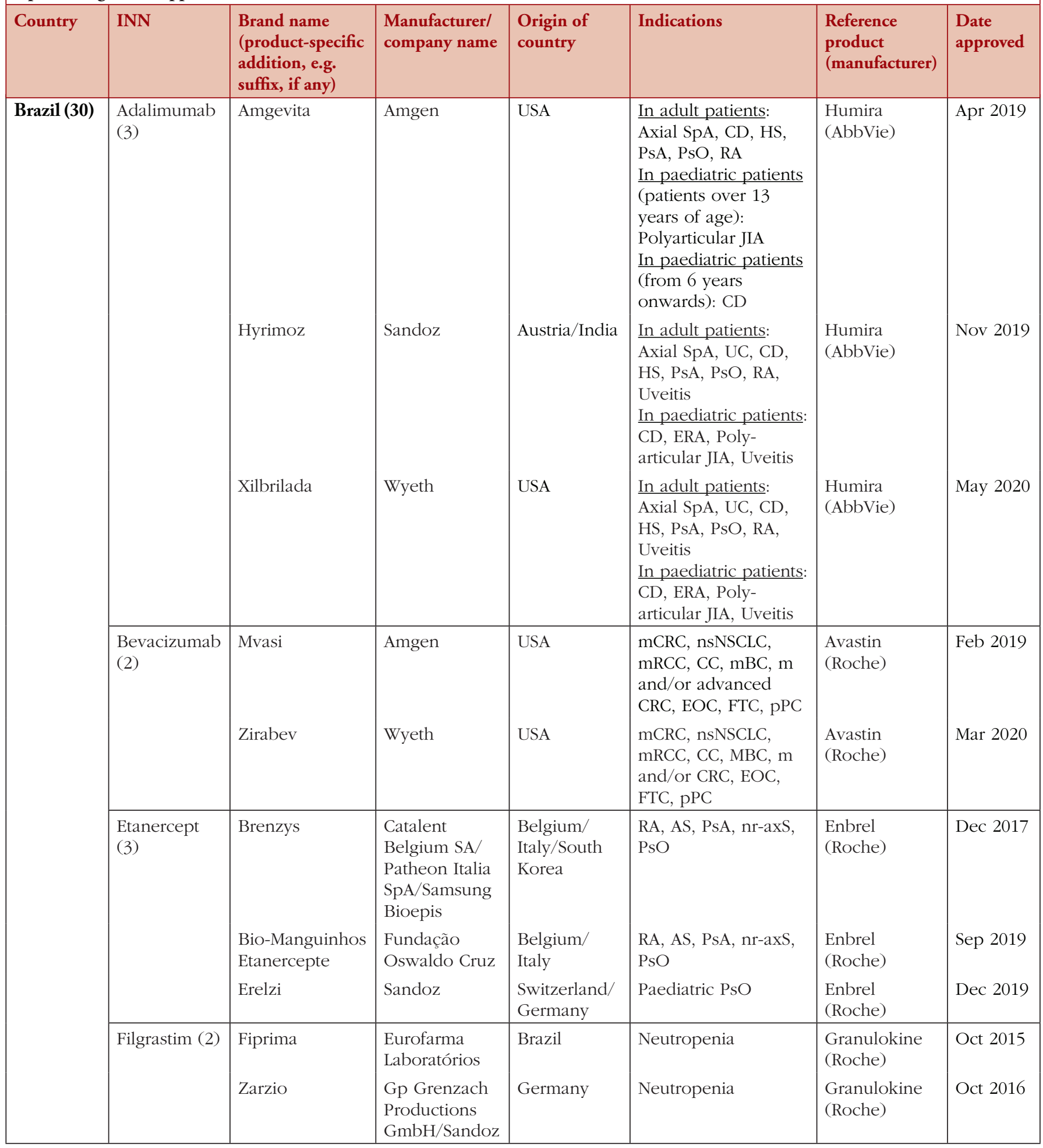




\section{Table 1: Similar biotherapeutic products/biosimilars approved in 16 countries (continued)}

\begin{tabular}{|c|c|c|c|c|c|c|c|}
\hline Country & INN & $\begin{array}{l}\text { Brand name } \\
\text { (product-specific } \\
\text { addition, e.g. } \\
\text { suffix, if any) }\end{array}$ & $\begin{array}{l}\text { Manufacturer/ } \\
\text { company name }\end{array}$ & $\begin{array}{l}\text { Origin of } \\
\text { country }\end{array}$ & Indications & $\begin{array}{l}\text { Reference } \\
\text { product } \\
\text { (manufacturer) }\end{array}$ & $\begin{array}{l}\text { Date } \\
\text { approved }\end{array}$ \\
\hline \multirow[t]{12}{*}{ Brazil (30) } & \multirow[t]{3}{*}{$\begin{array}{l}\text { Infliximab } \\
\text { (3) }\end{array}$} & Remsima & Celltrion Inc & South Korea & $\begin{array}{l}\text { RA, AS, PsA, PsO, CD, } \\
\text { Fistulizing CD, UC }\end{array}$ & $\begin{array}{l}\text { Remicade } \\
\text { (Janssen-Cilag) }\end{array}$ & Apr 2015 \\
\hline & & Renflexis & $\begin{array}{l}\text { Biogen Den- } \\
\text { mark Manu- } \\
\text { facturing Aps/ } \\
\text { Patheon Italia } \\
\text { SpA/Samsung } \\
\text { Bioepis }\end{array}$ & $\begin{array}{l}\text { Denmark/ } \\
\text { Italy } \\
\text { South Korea }\end{array}$ & $\begin{array}{l}\text { RA, AS, PsA, PsO, } \\
\text { CD, UC }\end{array}$ & $\begin{array}{l}\text { Remicade } \\
\text { (Janssen-Cilag) }\end{array}$ & Jul 2018 \\
\hline & & Xilfya & $\begin{array}{l}\text { Pfizer Manu- } \\
\text { facturing NV }\end{array}$ & Belgium/USA & $\begin{array}{l}\text { RA, AS, PsA, PsO, CD, } \\
\text { Fistulizing CD, UC }\end{array}$ & $\begin{array}{l}\text { Remicade } \\
\text { (Janssen-Cilag) }\end{array}$ & May 2019 \\
\hline & \multirow{2}{*}{$\begin{array}{l}\text { Insulin } \\
\text { glargine (3) }\end{array}$} & Glargilin & $\begin{array}{l}\text { Gan \& Lee } \\
\text { Pharmaceuti- } \\
\text { cals }\end{array}$ & China & Diabetes & $\begin{array}{l}\text { Lantus } \\
\text { (Sanofi) }\end{array}$ & Jul 2018 \\
\hline & & Glatus & Aspen & India & Diabetes & $\begin{array}{l}\text { Lantus } \\
\text { (Sanofi) }\end{array}$ & Nov 2019 \\
\hline & $\begin{array}{l}\text { Insulin } \\
\text { isophane }\end{array}$ & Visulin $\mathrm{N}$ & $\begin{array}{l}\text { Biocon } \\
\text { Limited } \\
\end{array}$ & India & Diabetes & $\begin{array}{l}\text { Novolin N } \\
\text { (Novo Nordisk) }\end{array}$ & Oct 2017 \\
\hline & $\begin{array}{l}\text { Human } \\
\text { insulin }\end{array}$ & Insuliv R & $\begin{array}{l}\text { Biocon } \\
\text { Limited }\end{array}$ & India & Diabetes & $\begin{array}{l}\text { Novolin R } \\
\text { (Novo Nordisk) }\end{array}$ & Mar 2018 \\
\hline & Insulin lispro & Admelog & Sanofi & Germany & Diabetes & $\begin{array}{l}\text { Humalog (Eli } \\
\text { Lilly) }\end{array}$ & Sep 2018 \\
\hline & \multirow[t]{4}{*}{$\begin{array}{l}\text { Rituximab } \\
\text { (4) }\end{array}$} & Riximyo & $\begin{array}{l}\text { Lek pharma- } \\
\text { ceuticals d d/ } \\
\text { Sandoz }\end{array}$ & Slovenia & $\begin{array}{l}\text { RA, NHL, Leukaemia, } \\
\text { GPA, MPA }\end{array}$ & $\begin{array}{l}\text { MabThera } \\
\text { (Roche) }\end{array}$ & Apr 2019 \\
\hline & & Vivaxxia & $\begin{array}{l}\text { Libbs Farma- } \\
\text { cêutica Ltda }\end{array}$ & $\begin{array}{l}\text { Brazil (Tech } \\
\text { transfer) }\end{array}$ & NHL, Leukaemia & MabThera & Jun 2019 \\
\hline & & Truxima & $\begin{array}{l}\text { Celltrion } \\
\text { Healthcare }\end{array}$ & $\begin{array}{l}\text { Republic of } \\
\text { Korea }\end{array}$ & $\begin{array}{l}\text { RA, NHL, Leukaemia, } \\
\text { GPA, MPA }\end{array}$ & $\begin{array}{l}\text { MabThera } \\
\text { (Roche) }\end{array}$ & Oct 2019 \\
\hline & & Ruxience & Wyeth & Belgium & $\begin{array}{l}\text { RA, NHL, Leukaemia, } \\
\text { GPA, MPA }\end{array}$ & $\begin{array}{l}\text { MabThera } \\
\text { (Roche) }\end{array}$ & May 2020 \\
\hline
\end{tabular}




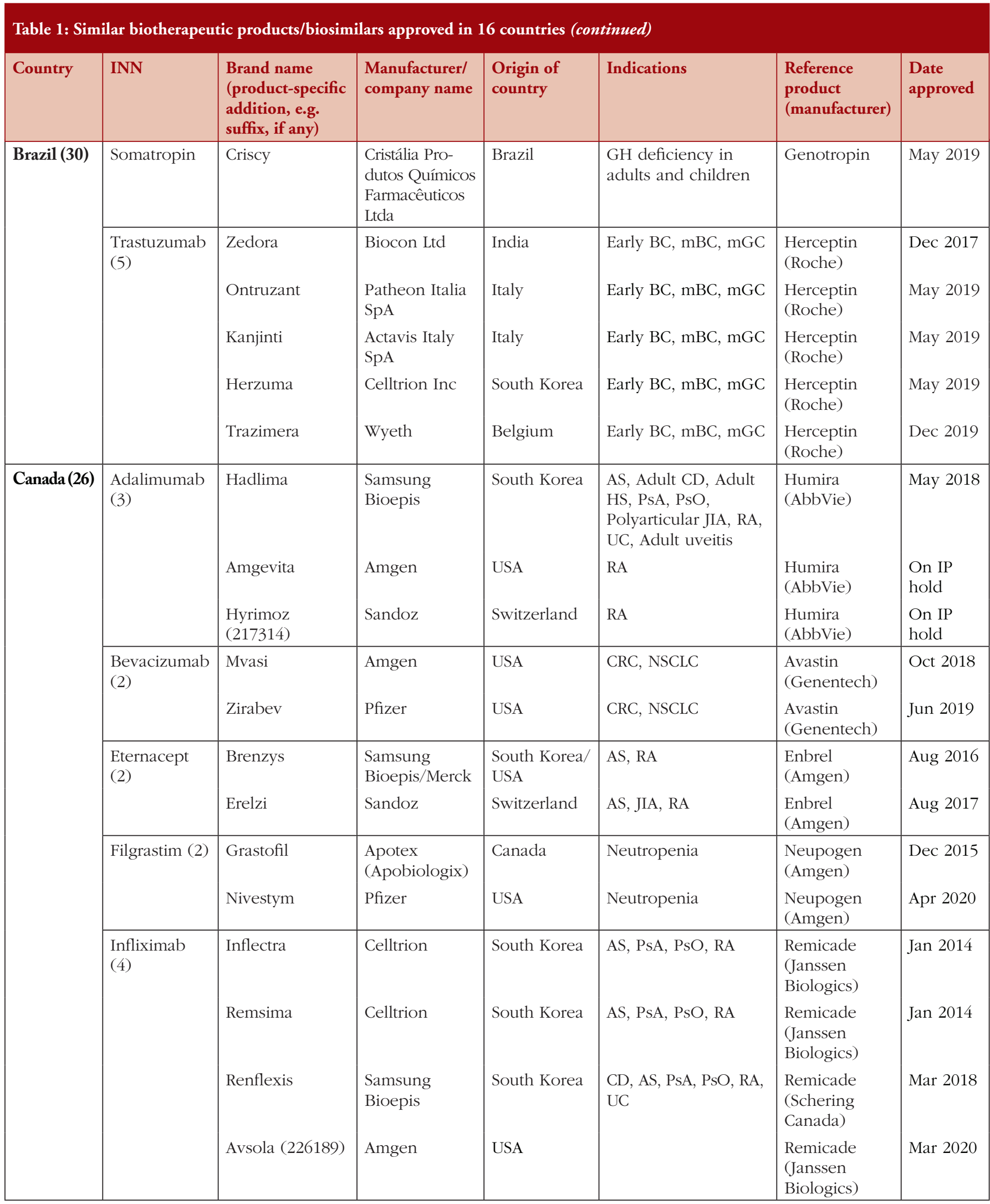


Table 1: Similar biotherapeutic products/biosimilars approved in 16 countries (continued)

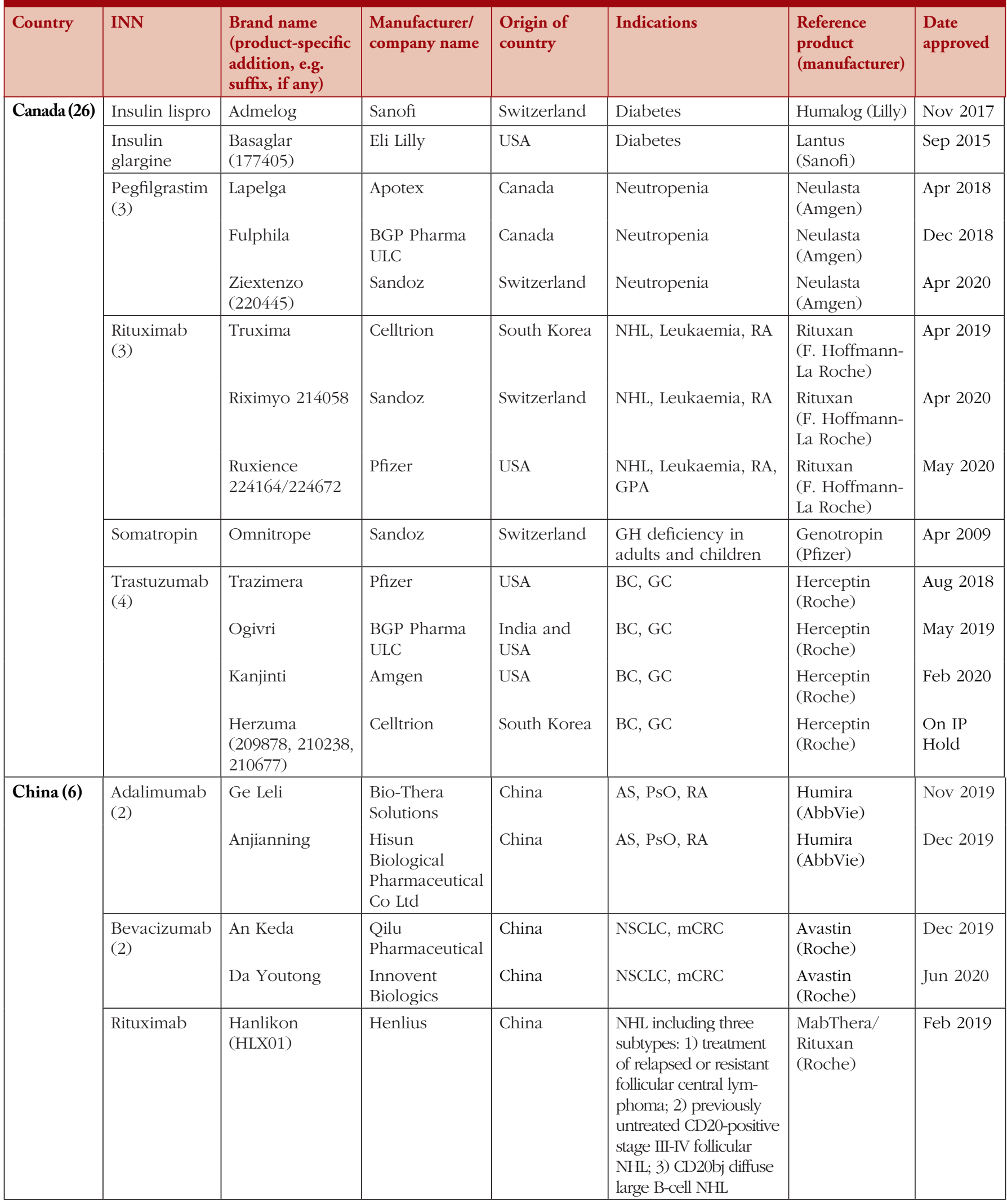




\begin{tabular}{|c|c|c|c|c|c|c|}
\hline INN & $\begin{array}{l}\text { Brand name } \\
\text { (product-specific } \\
\text { addition, e.g. } \\
\text { suffix, if any) }\end{array}$ & $\begin{array}{l}\text { Manufacturer/ } \\
\text { company name }\end{array}$ & $\begin{array}{l}\text { Origin of } \\
\text { country }\end{array}$ & Indications & $\begin{array}{l}\text { Reference } \\
\text { product } \\
\text { (manufacturer) }\end{array}$ & $\begin{array}{l}\text { Date } \\
\text { approved }\end{array}$ \\
\hline Trastuzumab & TBD (HLX02) & Henlius & China & TBD (HLX02) & $\begin{array}{l}\text { Herceptin } \\
\text { (Roche) }\end{array}$ & $\begin{array}{l}\text { Finish } \\
\text { review in } \\
\text { Jul 2020; } \\
\text { target for } \\
\text { approval } \\
\text { in Aug } \\
2020\end{array}$ \\
\hline \multirow[t]{7}{*}{\begin{tabular}{|l|} 
Adalimumab \\
(11 approved, \\
3 withdrawn)
\end{tabular}} & $\begin{array}{l}\text { Amgevita } \\
\text { Solymbic }\end{array}$ & Amgen & $U S A$ & $\begin{array}{l}\text { AS, CD, Juvenile RA, } \\
\text { PsO, PsA, RA, UC } \\
A S, C D, H S, P S O, P S A, \\
R A, U C\end{array}$ & $\begin{array}{l}\text { Humira } \\
\text { (AbbVie) }\end{array}$ & $\begin{array}{l}\text { Mar } 2017 \\
\text { With- } \\
\text { drawn } \\
\text { Jun } 2018\end{array}$ \\
\hline & Imraldi & $\begin{array}{l}\text { Samsung } \\
\text { Bioepis }\end{array}$ & South Korea & $\begin{array}{l}\text { AS, JIA, CD, HS, PsA, } \\
\text { PsO, RA, UC, Uveitis }\end{array}$ & $\begin{array}{l}\text { Humira } \\
\text { (AbbVie) }\end{array}$ & Aug 2017 \\
\hline & Cyltezo & $\begin{array}{l}\text { Boehringer } \\
\text { Ingelheim }\end{array}$ & Germany & $\begin{array}{l}C D, H S, J U A, P s O \\
P S A, R A, U C, \text { Uveitis }\end{array}$ & $\begin{array}{l}\text { Humira } \\
\text { (AbbVie) }\end{array}$ & $\begin{array}{l}\text { Nov } 2017 \\
\text { With- } \\
\text { drawn } \\
\text { Jan } 2019\end{array}$ \\
\hline & Halimatoz & Sandoz & Switzerland & $\begin{array}{l}\text { AS, HS, JIA, PsA, } \\
\text { PoS, RA, Uveitis }\end{array}$ & $\begin{array}{l}\text { Humira } \\
\text { (AbbVie) }\end{array}$ & Jul 2018 \\
\hline & Idacio & Fresenius Kabi & Germany & $\begin{array}{l}\text { AS, CD, HS, PsO, PsA, } \\
\text { RA, Juvenile RA, UC, } \\
\text { Uveitis }\end{array}$ & $\begin{array}{l}\text { Humira } \\
\text { (AbbVie) }\end{array}$ & Jan 2019 \\
\hline & Kromeya & Fresenius Kabi & Germany & $\begin{array}{l}\text { AS, CD, PSO, PSA, RA, } \\
\text { Juvenile RA, UC, Uveitis }\end{array}$ & $\begin{array}{l}\text { Humira } \\
\text { (AbbVie) }\end{array}$ & $\begin{array}{l}\text { Jan } 2019 \\
\text { With- } \\
\text { drawn } \\
\text { Dec } 2019\end{array}$ \\
\hline & Amsparity & Pfizer Europe & Belgium & $\begin{array}{l}\text { AS, CD, HS, PsO, PsA, } \\
\text { RA, Juvenile RA, UC, } \\
\text { Uveitis }\end{array}$ & $\begin{array}{l}\text { Humira } \\
\text { (AbbVie) }\end{array}$ & Feb 2020 \\
\hline \multirow[t]{3}{*}{$\begin{array}{l}\text { Bevacizumab } \\
(4)\end{array}$} & Mvasi & Amgen & USA & $\begin{array}{l}\text { BC, FTC, NSCLC, OC, } \\
\text { PC, RCC }\end{array}$ & $\begin{array}{l}\text { Avastin } \\
\text { (Genentech) }\end{array}$ & Jan 2018 \\
\hline & Zirabevv & Pfizer & USA & $\begin{array}{l}\text { CRC, BC, NSCLC, RCC, } \\
\text { CC }\end{array}$ & $\begin{array}{l}\text { Avastin } \\
\text { (Roche) }\end{array}$ & Feb 2019 \\
\hline & Aybintio & $\begin{array}{l}\text { Samsung } \\
\text { Bioepis }\end{array}$ & Netherlands & $\begin{array}{l}\text { CRC, BC, NSCLC, RCC, } \\
\text { OC, CC }\end{array}$ & $\begin{array}{l}\text { Avastin } \\
\text { (Roche) }\end{array}$ & Aug 2020 \\
\hline
\end{tabular}




\section{Table 1: Similar biotherapeutic products/biosimilars approved in 16 countries (continued)}

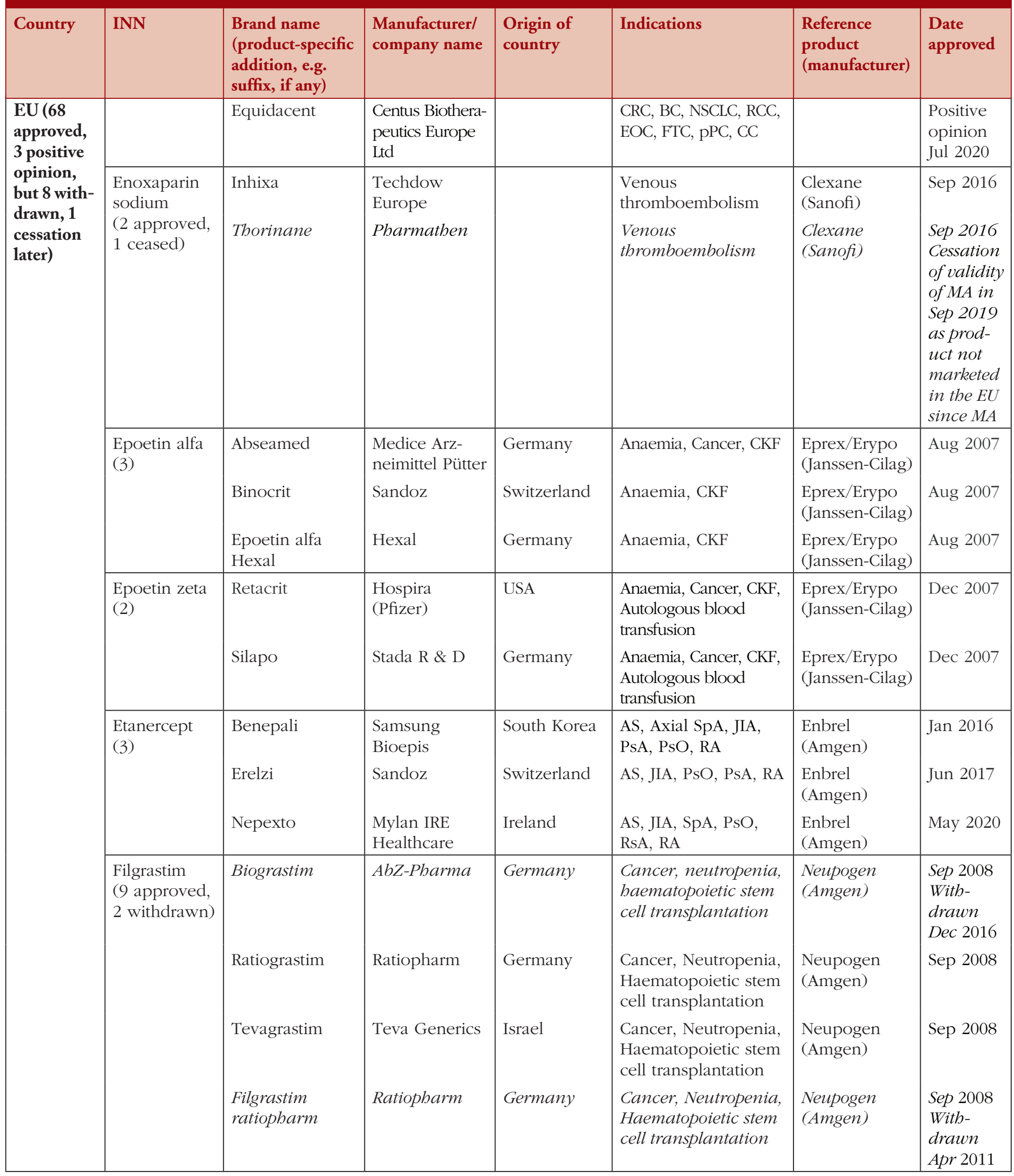




\section{Table 1: Similar biotherapeutic products/biosimilars approved in 16 countries (continued)}

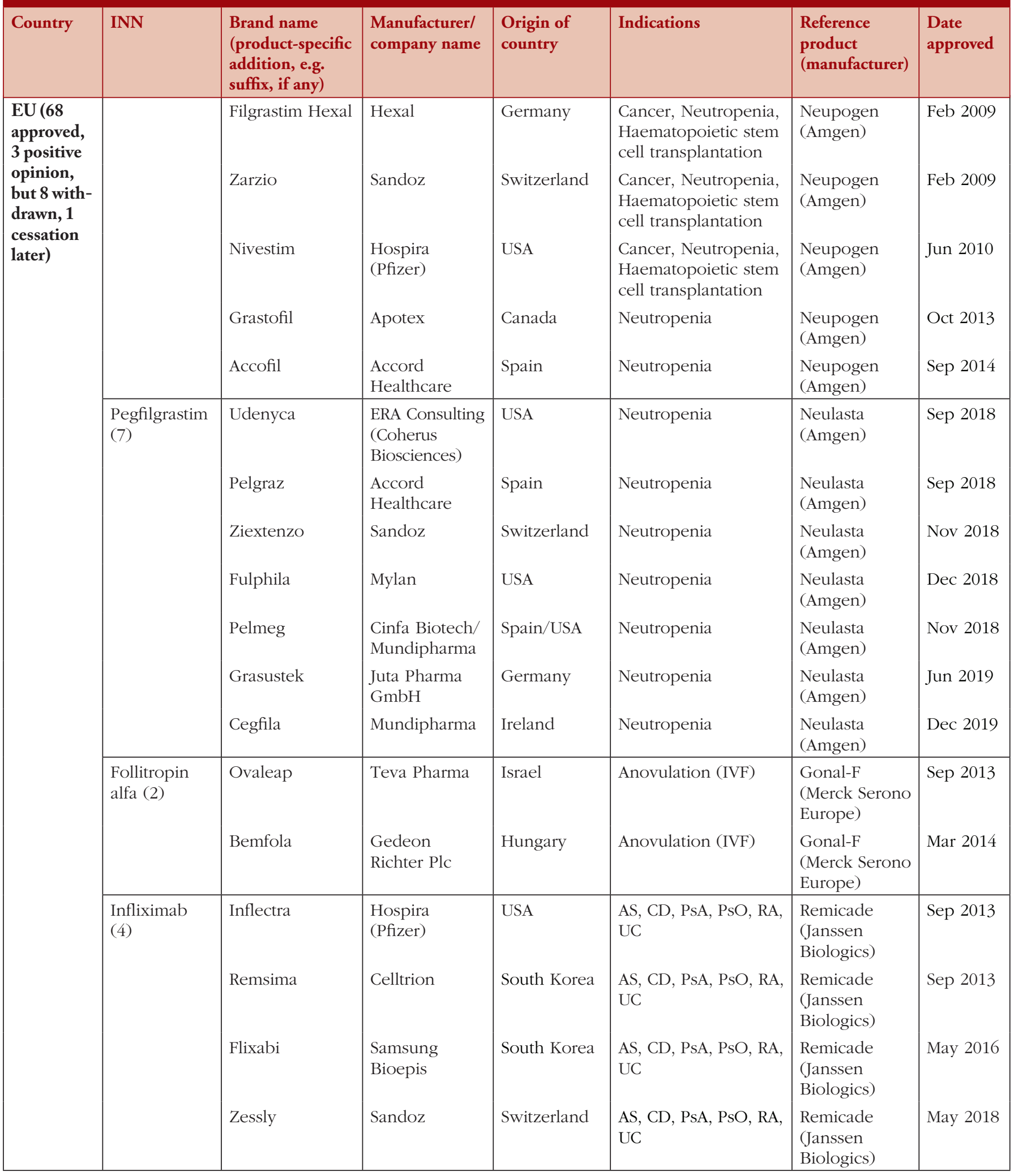




\section{Table 1: Similar biotherapeutic products/biosimilars approved in 16 countries (continued)}

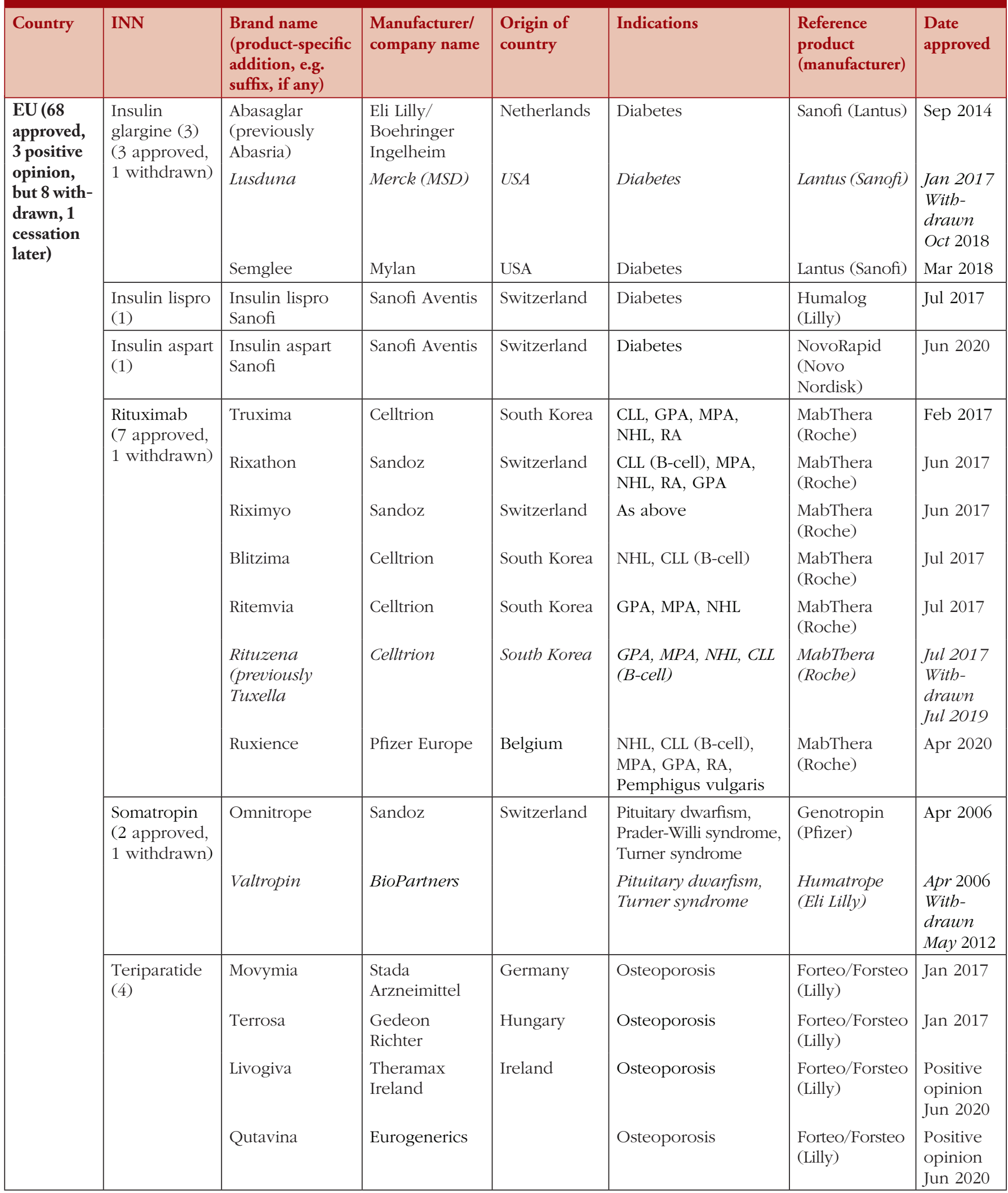




\section{Table 1: Similar biotherapeutic products/biosimilars approved in 16 countries (continued)}

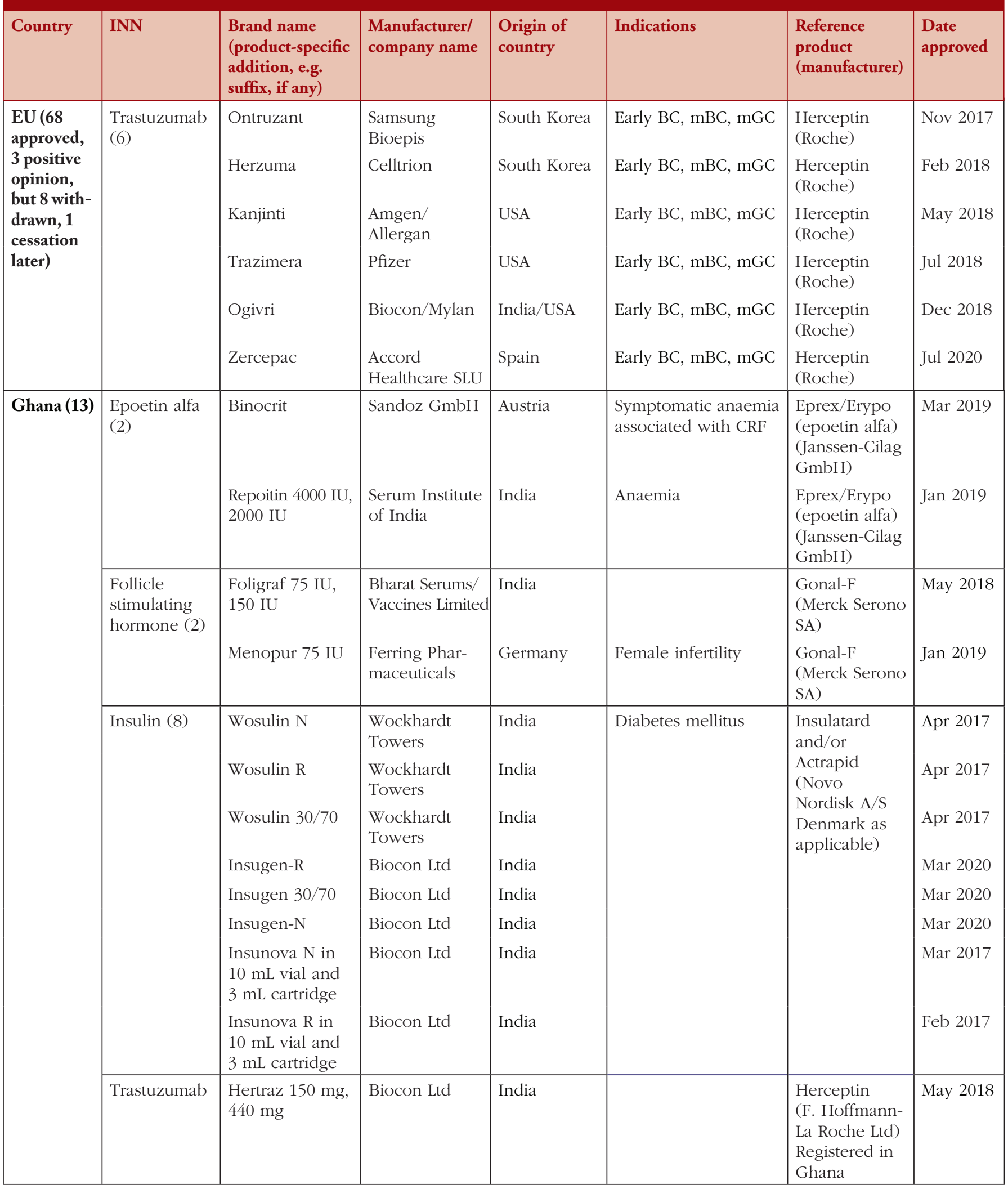




\section{Table 1: Similar biotherapeutic products/biosimilars approved in 16 countries (continued)}

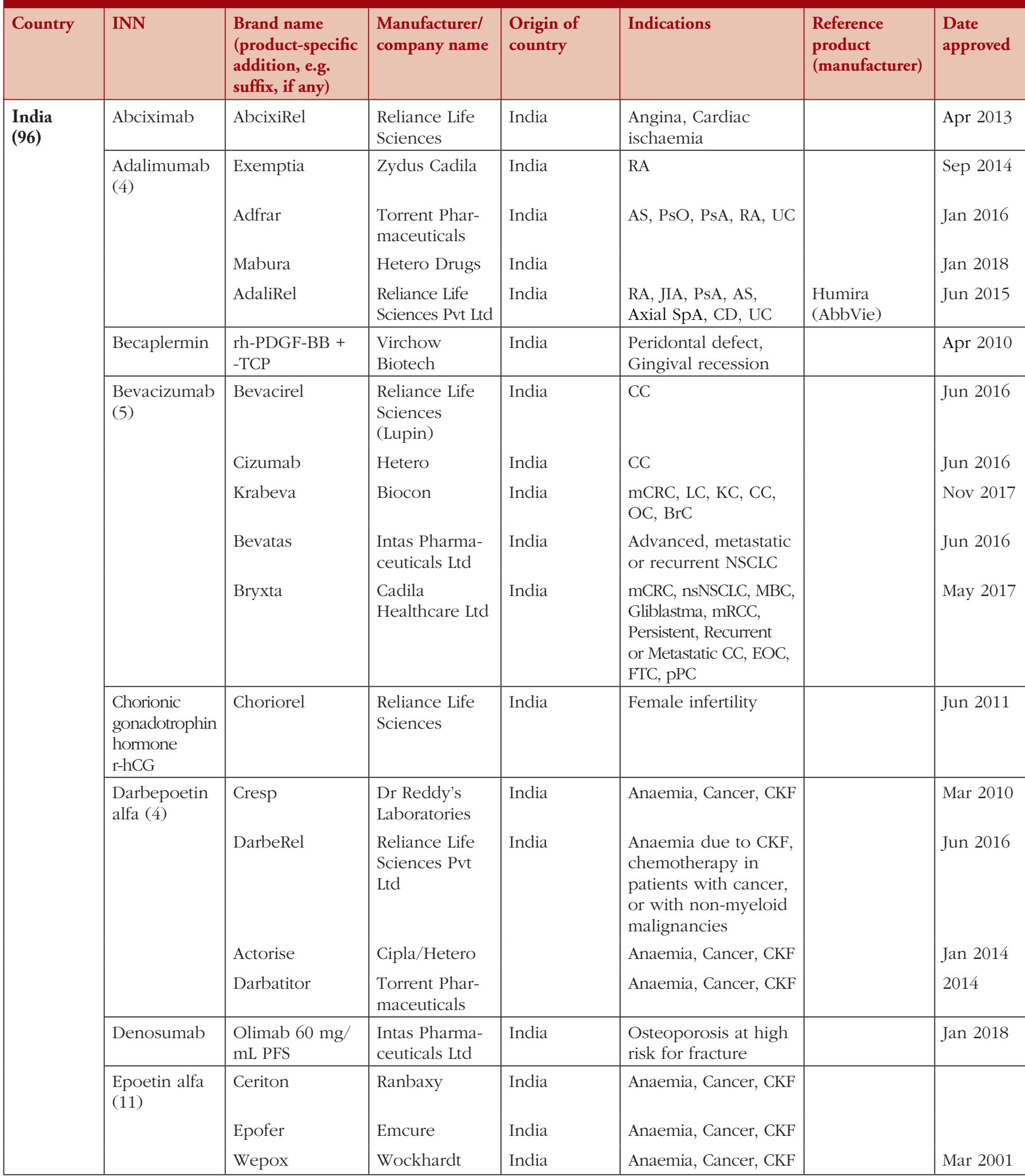




\section{Table 1: Similar biotherapeutic products/biosimilars approved in 16 countries (continued)}

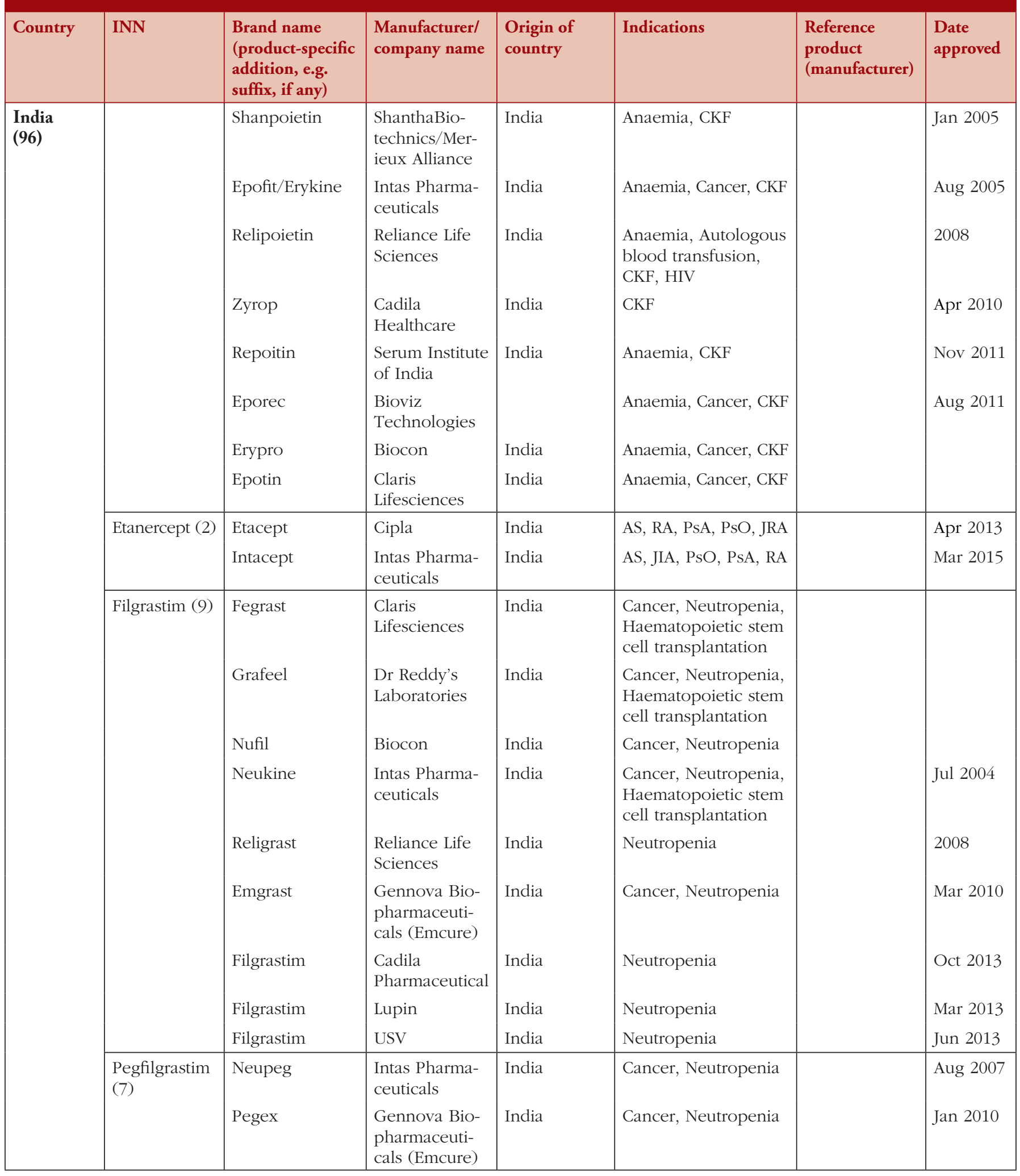


Table 1: Similar biotherapeutic products/biosimilars approved in 16 countries (continued)

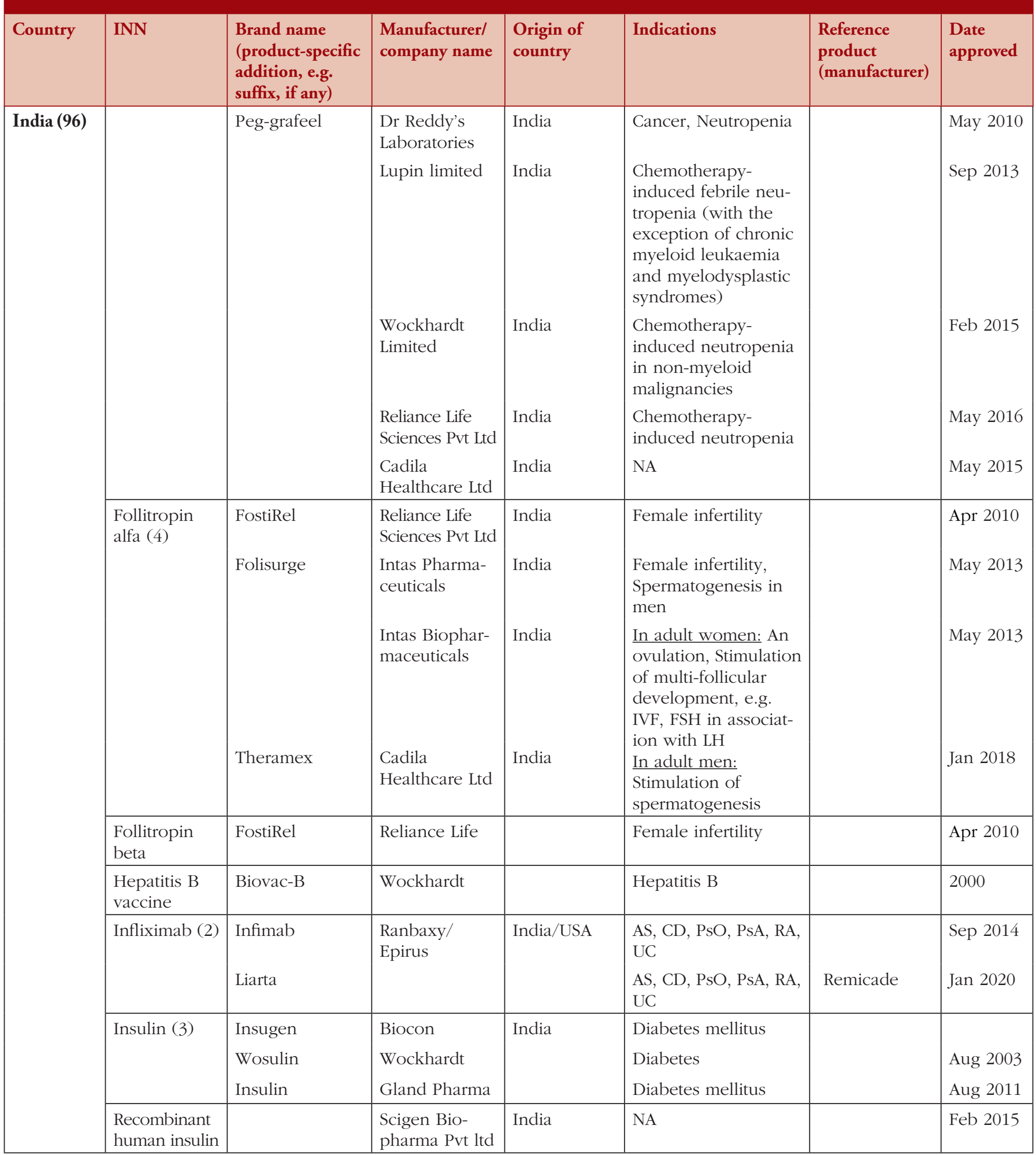

(Continued) 


\section{Table 1: Similar biotherapeutic products/biosimilars approved in 16 countries (continued)}

\begin{tabular}{|c|c|c|c|c|c|c|c|}
\hline Country & INN & $\begin{array}{l}\text { Brand name } \\
\text { (product-specific } \\
\text { addition, e.g. } \\
\text { suffix, if any) }\end{array}$ & $\begin{array}{l}\text { Manufacturer/ } \\
\text { company name }\end{array}$ & $\begin{array}{l}\text { Origin of } \\
\text { country }\end{array}$ & Indications & $\begin{array}{l}\text { Reference } \\
\text { product } \\
\text { (manufacturer) }\end{array}$ & $\begin{array}{l}\text { Date } \\
\text { approved }\end{array}$ \\
\hline \multirow[t]{9}{*}{ India (96) } & $\begin{array}{l}\text { Insulin } \\
\text { glargine (2) }\end{array}$ & $\begin{array}{l}\text { Basalog } \\
\text { Glaritus }\end{array}$ & $\begin{array}{l}\text { Biocon } \\
\text { Wockhardt }\end{array}$ & India & $\begin{array}{l}\text { Diabetes } \\
\text { Diabetes }\end{array}$ & & $\begin{array}{l}2009 \\
\text { Mar } 2009\end{array}$ \\
\hline & $\begin{array}{l}\text { Interferon } \\
\text { alfa-2b (4) }\end{array}$ & $\begin{array}{l}\text { Shanferon } \\
\text { Reliferon } \\
\text { Intalfa } \\
\text { Zavinex }\end{array}$ & $\begin{array}{l}\text { ShanthaBio- } \\
\text { technics/Mer- } \\
\text { ieux Alliance } \\
\text { Reliance Life } \\
\text { Sciences } \\
\text { Intas Pharma- } \\
\text { ceuticals } \\
\text { Cadila } \\
\text { Healthcare }\end{array}$ & $\begin{array}{l}\text { India } \\
\text { India } \\
\text { India }\end{array}$ & $\begin{array}{l}\text { BCR-ABL positive, } \\
\text { Carcinoid tumour, } \\
\text { Chronic hepatitis B, } \\
\text { Chronic hepatitis C, } \\
\text { Chronic myelogenous } \\
\text { leukaemia, Follicular } \\
\text { lymphoma, Hairy } \\
\text { cell leukaemia, } \\
\text { Melanoma, Multiple } \\
\text { myeloma } \\
\text { Chronic hepatitis B, } \\
\text { Chronic hepatitis C }\end{array}$ & & $\begin{array}{l}\text { Apr } 2002 \\
2008 \\
\text { Apr } 2017 \\
\text { Jun } 2011\end{array}$ \\
\hline & $\begin{array}{l}\text { Pegylated } \\
\text { recombinant } \\
\text { human } \\
\text { interferon } \\
\text { alfa-2b (2) }\end{array}$ & & $\begin{array}{l}\text { Cadila } \\
\text { Healthcare Ltd } \\
\text { Intas Biophar- } \\
\text { maceuticals }\end{array}$ & $\begin{array}{l}\text { India } \\
\text { India }\end{array}$ & $\begin{array}{l}\text { Chronic hepatitis B } \\
\text { and Chronic hepatitis } \\
\text { C patients } \\
\text { Chronic hepatitis C } \\
\text { and Chronic hepatitis } \\
\text { B }\end{array}$ & & $\begin{array}{l}\text { Jun } 2011 \\
\text { Apr } 2013\end{array}$ \\
\hline & $\begin{array}{l}\text { Interferon } \\
\text { beta-1a }\end{array}$ & Relibeta & $\begin{array}{l}\text { Reliance Life } \\
\text { Sciences }\end{array}$ & India & Multiple sclerosis & & May 2011 \\
\hline & $\begin{array}{l}\text { Recombinant } \\
\text { interferon } \\
\text { beta-1a }\end{array}$ & & $\begin{array}{l}\text { Reliance Life } \\
\text { Sciences Pvt } \\
\text { Ltd }\end{array}$ & India & $\begin{array}{l}\text { For the treatment of } \\
\text { relapsing multiple } \\
\text { sclerosis }\end{array}$ & & May 2011 \\
\hline & $\begin{array}{l}\text { Itolizumab } \\
\text { (T1hmAb) } \\
\text { injection }\end{array}$ & & Biocon Ltd & India & $\begin{array}{l}\text { For the treatment of } \\
\text { patients with active to } \\
\text { moderate to severe } \\
\text { chronic plaque pso- } \\
\text { riasis who are candi- } \\
\text { dates for systemic } \\
\text { therapy }\end{array}$ & & Dec 2012 \\
\hline & Molgramostim & Molgramostim & $\begin{array}{l}\text { Zenotech } \\
\text { Laboratories }\end{array}$ & India & Neutropenia & & May 2013 \\
\hline & Omalizumab & $\begin{array}{l}\text { Not yet in } \\
\text { market }\end{array}$ & $\begin{array}{l}\text { Reliance Life } \\
\text { Sciences Pvt } \\
\text { Ltd, Dhirubhai } \\
\text { Ambani Life } \\
\text { Sciences Centre }\end{array}$ & India & $\begin{array}{l}\text { Asthma, Chronic } \\
\text { Idiopathic Urticaria }\end{array}$ & Xolair & Feb 2020 \\
\hline & $\begin{array}{l}\text { Ranibizumab } \\
\text { (2) }\end{array}$ & & $\begin{array}{l}\text { Intas Pharma- } \\
\text { ceuticals Ltd }\end{array}$ & India & $\begin{array}{l}\text { Neovascular AMD, } \\
\text { DME, Macular } \\
\text { edema following } \\
\text { RVO, Vaisula impara- } \\
\text { ment due to CNV } \\
\text { secondary to patho- } \\
\text { logical myopia }\end{array}$ & & Feb 2015 \\
\hline
\end{tabular}


Table 1: Similar biotherapeutic products/biosimilars approved in 16 countries (continued)

\begin{tabular}{|c|c|c|c|c|c|c|c|}
\hline Country & INN & $\begin{array}{l}\text { Brand name } \\
\text { (product-specific } \\
\text { addition, e.g. } \\
\text { suffix, if any) }\end{array}$ & $\begin{array}{l}\text { Manufacturer/ } \\
\text { company name }\end{array}$ & $\begin{array}{l}\text { Origin of } \\
\text { country }\end{array}$ & Indications & $\begin{array}{l}\text { Reference } \\
\text { product } \\
\text { (manufacturer) }\end{array}$ & $\begin{array}{l}\text { Date } \\
\text { approved }\end{array}$ \\
\hline \multirow{7}{*}{ India (96) } & $\begin{array}{l}\text { Rasburicase } \\
\text { injection }\end{array}$ & Rasburicase & $\begin{array}{l}\text { Virchow } \\
\text { Biotech Pvt Ltd }\end{array}$ & India & $\begin{array}{l}\text { Malignancy associated } \\
\text { hyperuricemia }\end{array}$ & & Aug 2012 \\
\hline & $\begin{array}{l}\text { Recombinant } \\
\text { human granu- } \\
\text { locyte macro- } \\
\text { phage colony } \\
\text { stimulating } \\
\text { factor (Mol- } \\
\text { gramostim) } \\
\end{array}$ & & $\begin{array}{l}\text { Zenotech } \\
\text { Laboratories }\end{array}$ & India & $\begin{array}{l}\text { Reduction of the } \\
\text { severity of neutropenia } \\
\text { in patients receiving } \\
\text { myelosuppressive } \\
\text { therapy (cancer } \\
\text { chemotherapy) }\end{array}$ & & May 2013 \\
\hline & $\begin{array}{l}\text { Recombinant } \\
\text { human } \\
\text { growth } \\
\text { hormone }\end{array}$ & & USV Limited & India & $\begin{array}{l}\text { Treatment of pre- } \\
\text { pubertal children ( } 4 \\
\text { to } 12 \text { years) with } \\
\text { growth hormone } \\
\text { deficiency }\end{array}$ & & Jun 2013 \\
\hline & & RituxiRel & $\begin{array}{l}\text { Reliance Life } \\
\text { Sciences }\end{array}$ & India & NHL, RA & & Feb 2015 \\
\hline & & Maball & Hetero Group & India & Lymphoma, NHL & & Feb 2015 \\
\hline & & Acellbia & Biocad & Russia & NHL, CLL (B-cell) & & Jul 2017 \\
\hline & Somatropin & & $\begin{array}{l}\text { Reliance Life } \\
\text { Sciences Pvt } \\
\text { Ltd }\end{array}$ & India & $\begin{array}{l}\text { In paediatrics patients: } \\
\text { 1) growth failure } \\
\text { due to inadequate } \\
\text { secretion of GH } \\
\text { 2) short stature } \\
\text { associated with } \\
\text { Noonan syndrome } \\
\text { or born small for } \\
\text { gestational age with } \\
\text { no catch-up growth } \\
\text { by age } 2-4 \text { years }\end{array}$ & & May 2018 \\
\hline
\end{tabular}




\section{Table 1: Similar biotherapeutic products/biosimilars approved in 16 countries (continued)}

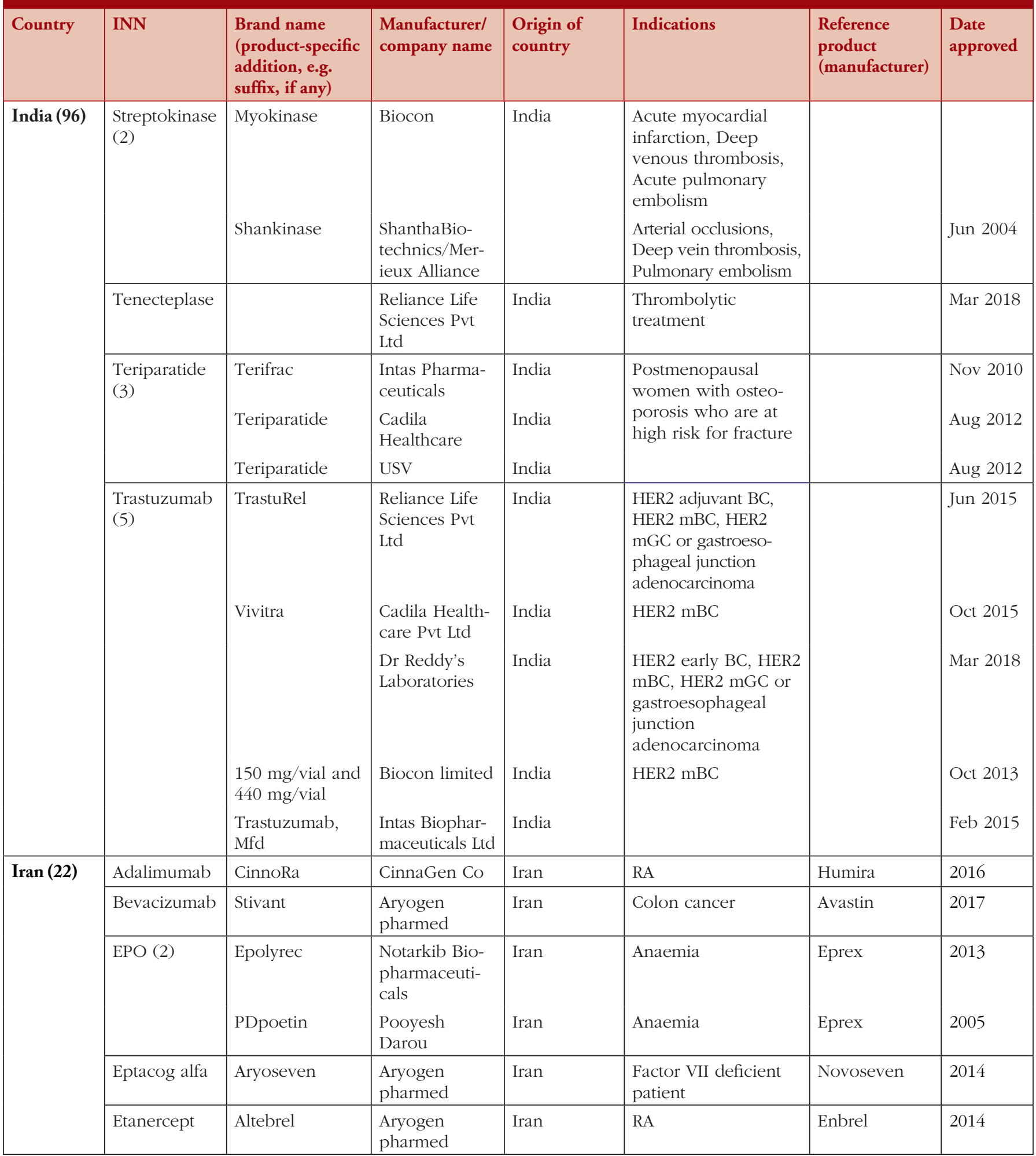




\begin{tabular}{|c|c|c|c|c|c|c|c|}
\hline Country & INN & $\begin{array}{l}\text { Brand name } \\
\text { (product-specific } \\
\text { addition, e.g. } \\
\text { suffix, if any) }\end{array}$ & $\begin{array}{l}\text { Manufacturer/ } \\
\text { company name }\end{array}$ & $\begin{array}{l}\text { Origin of } \\
\text { country }\end{array}$ & Indications & $\begin{array}{l}\text { Reference } \\
\text { product } \\
\text { (manufacturer) }\end{array}$ & $\begin{array}{l}\text { Date } \\
\text { approved }\end{array}$ \\
\hline \multirow[t]{9}{*}{$\operatorname{Iran}(22)$} & Filgrastim (2) & PDgrastim & $\begin{array}{l}\text { Pooyesh } \\
\text { Darou }\end{array}$ & Iran & $\begin{array}{l}\text { Neutropenia after } \\
\text { Chemotherapy }\end{array}$ & $\begin{array}{l}\text { Zarzio, } \\
\text { Neupogen }\end{array}$ & 2013 \\
\hline & \multirow[t]{2}{*}{$\begin{array}{l}\text { Pegylated- } \\
\text { filgrastim (2) }\end{array}$} & PegaGen & CinnaGen Co & Iran & $\begin{array}{l}\text { Neutropenia after } \\
\text { chemotherapy }\end{array}$ & Neulasta & 2014 \\
\hline & & PDlasta & $\begin{array}{l}\text { Pooyesh } \\
\text { Darou }\end{array}$ & Iran & $\begin{array}{l}\text { Neutropenia after } \\
\text { chemotherapy }\end{array}$ & Neulasta & 2015 \\
\hline & $\begin{array}{l}\text { PEG- } \\
\text { interferon } \\
\text { alpha-2b }\end{array}$ & PD-feron & $\begin{array}{l}\text { Pooyesh } \\
\text { Darou }\end{array}$ & Iran & Immunomodulator & PEG-Intron & 2010 \\
\hline & \multirow[t]{3}{*}{$\begin{array}{l}\text { Interferon } \\
\text { beta-1a (3) }\end{array}$} & CinnoVex & CinnaGen Co & & Multiple sclerosis & $\begin{array}{l}\text { Avonex, Rebif, } \\
\text { Rebidose }\end{array}$ & 2011 \\
\hline & & Actovex & Actover & Iran & Multiple sclerosis & $\begin{array}{l}\text { Avonex, Rebif, } \\
\text { Rebidose }\end{array}$ & 2011 \\
\hline & & Reecigen & CinnaGen Co & Iran & Multiple sclerosis & $\begin{array}{l}\text { Avonex, Rebif, } \\
\text { Rebidose }\end{array}$ & 2013 \\
\hline & Trastuzumab & Aryotrust & $\begin{array}{l}\text { Aryogen } \\
\text { pharmed }\end{array}$ & Iran & $\mathrm{BC}$ & Herceptin & 2014 \\
\hline & $\begin{array}{l}\text { Insulin } \mathrm{N} \\
\text { Insulin } \mathrm{R}\end{array}$ & $\begin{array}{l}\text { Vitasulin N } \\
\text { Vitasulin R }\end{array}$ & Vitan pharmed & Iran & Diabetes & $\begin{array}{l}\text { Insulatard } \\
\text { actrapid }\end{array}$ & 2017 \\
\hline \multirow[t]{4}{*}{ Japan (26) } & Adalimumab & $\begin{array}{l}\text { Adalimumab BS } \\
\text { [Adalimumab } \\
\text { BS1] }\end{array}$ & $\begin{array}{l}\text { Kyowa Kirin } \\
\text { Fujifilm } \\
\text { Biologics } \\
\end{array}$ & Japan & RA, PsO, CD & $\begin{array}{l}\text { Humira } \\
\text { Adalimumab } \\
\text { (AbbVie) } \\
\end{array}$ & Jun 2020 \\
\hline & $\begin{array}{l}\text { Agalsidase } \\
\text { Beta }\end{array}$ & $\begin{array}{l}\text { Agalsidase Beta } \\
\text { BS [Agalsidase } \\
\text { Beta BS1] }\end{array}$ & JCR Pharma & Japan & Fabry disease & $\begin{array}{l}\text { Fabrazyme } \\
\text { injection } \\
\text { Agalsidase Beta } \\
\text { (Genzyme) }\end{array}$ & Sep 2018 \\
\hline & \multirow[t]{2}{*}{$\begin{array}{l}\text { Bevacizumab } \\
\text { (2) }\end{array}$} & $\begin{array}{l}\text { Bevacizumab BS } \\
{[\text { Bevacizumab }} \\
\text { BS1] }\end{array}$ & Pfizer & USA & $\begin{array}{l}\text { Progress/recurrence } \\
\text { CRC }\end{array}$ & $\begin{array}{l}\text { Avastin } \\
\text { Bevacizumab } \\
\text { (Chugai) }\end{array}$ & Jun 2019 \\
\hline & & $\begin{array}{l}\text { Bevacizumab BS } \\
{[\text { Bevacizumab }} \\
\text { BS2] }\end{array}$ & $\begin{array}{l}\text { Daiichi } \\
\text { Sankyo }\end{array}$ & Japan & $\begin{array}{l}\text { Progress/recurrence } \\
\text { CRC }\end{array}$ & $\begin{array}{l}\text { Avastin } \\
\text { Bevacizumab } \\
\text { (Chugai) }\end{array}$ & Sep 2019 \\
\hline
\end{tabular}




\section{Table 1: Similar biotherapeutic products/biosimilars approved in 16 countries (continued)}

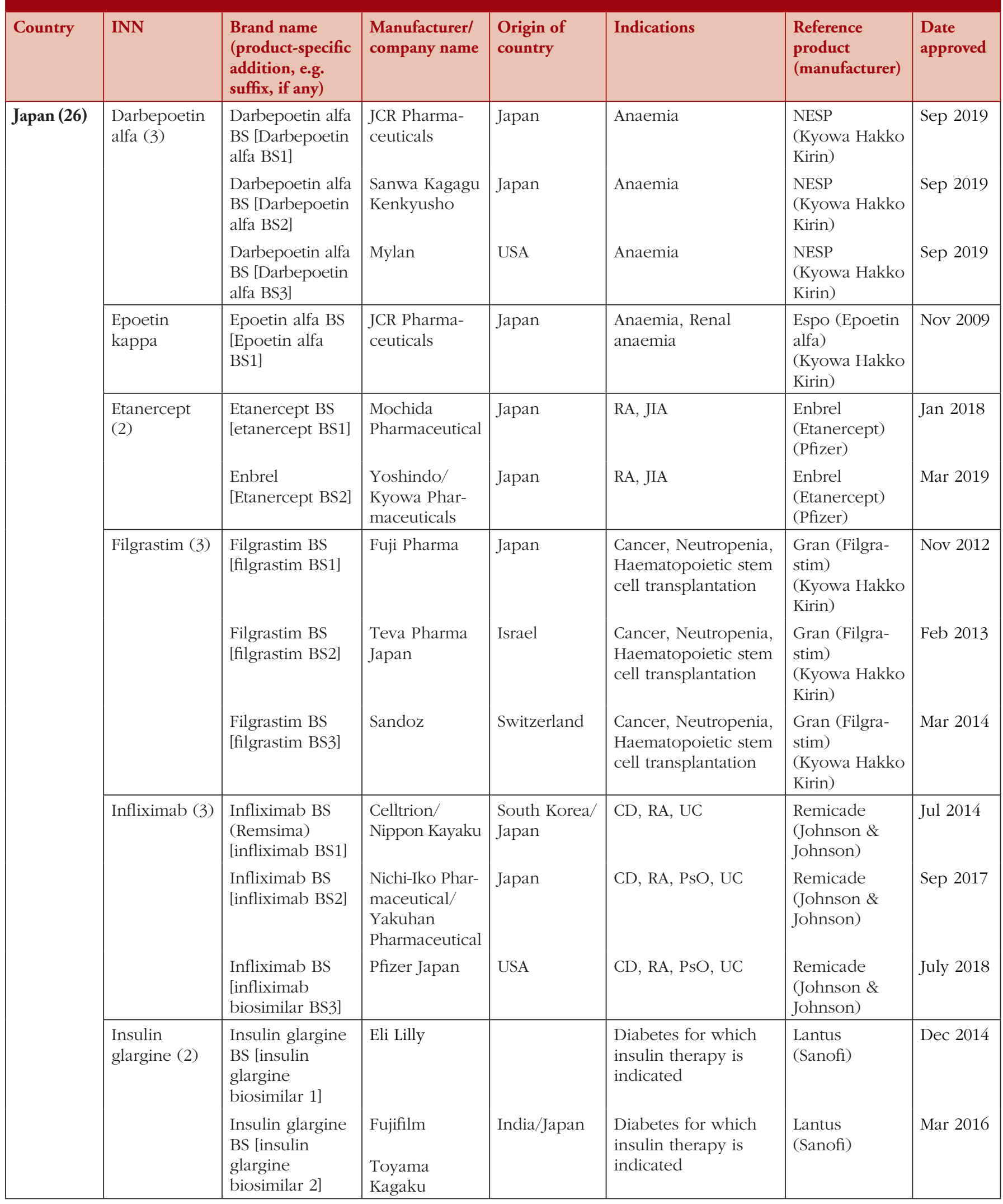




\section{Table 1: Similar biotherapeutic products/biosimilars approved in 16 countries (continued)}

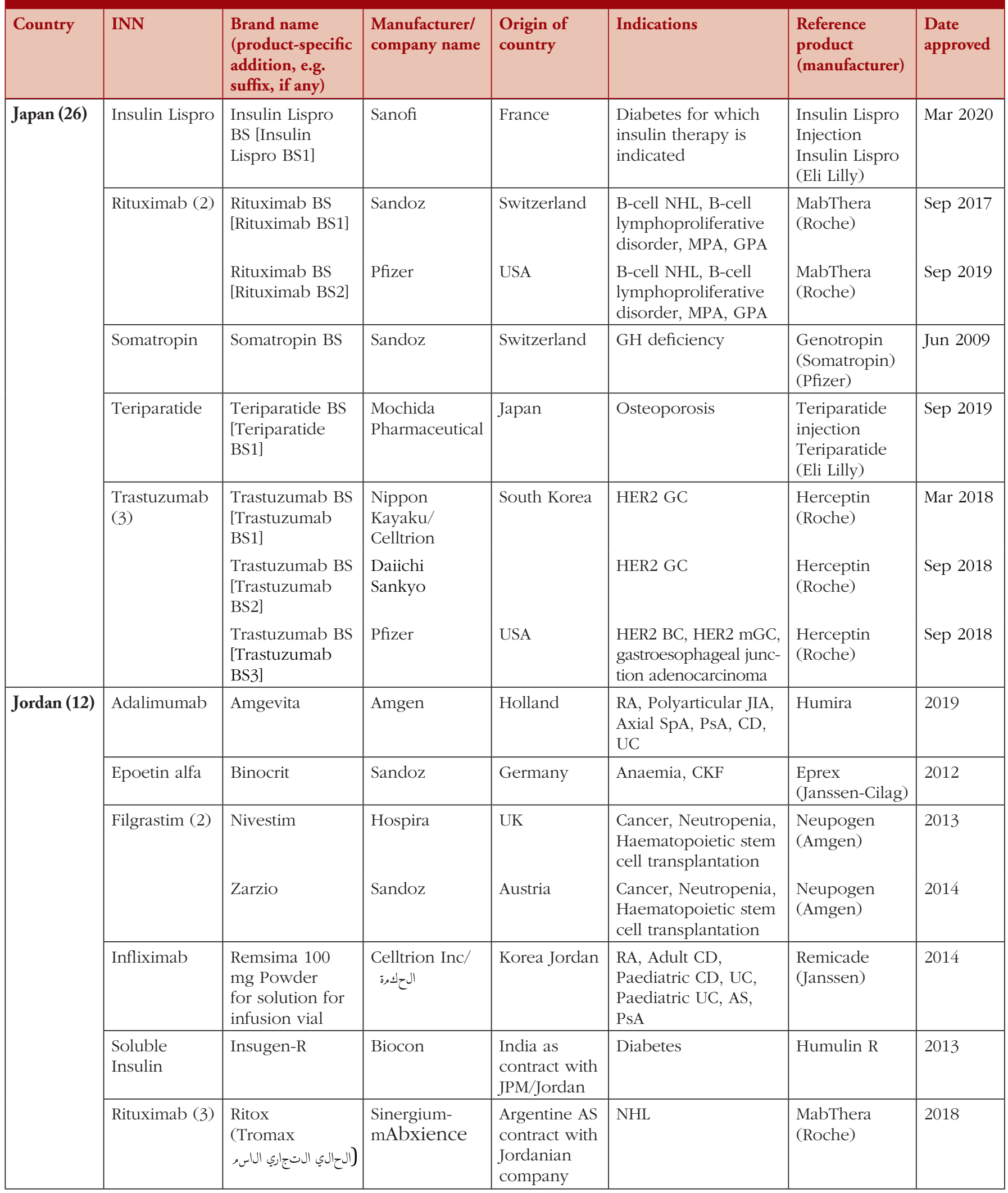




\section{Table 1: Similar biotherapeutic products/biosimilars approved in 16 countries (continued)}

\begin{tabular}{|c|c|c|c|c|c|c|c|}
\hline Country & INN & $\begin{array}{l}\text { Brand name } \\
\text { (product-specific } \\
\text { addition, e.g. } \\
\text { suffix, if any) }\end{array}$ & $\begin{array}{l}\text { Manufacturer/ } \\
\text { company name }\end{array}$ & $\begin{array}{l}\text { Origin of } \\
\text { country }\end{array}$ & Indications & $\begin{array}{l}\text { Reference } \\
\text { product } \\
\text { (manufacturer) }\end{array}$ & $\begin{array}{l}\text { Date } \\
\text { approved }\end{array}$ \\
\hline \multirow[t]{3}{*}{ Jordan (12) } & & $\begin{array}{l}\text { Truxima } \\
\text { Rixathon }\end{array}$ & $\begin{array}{l}\text { Celltrion Inc/ } \\
\text { لحك,رةا } \\
\text { Sandoz GmbH }\end{array}$ & $\begin{array}{l}\text { Korea/Jordan } \\
\text { Austria }\end{array}$ & $\begin{array}{l}\text { NHL, CLL, PA, GPA, } \\
\text { MPA } \\
\text { Follicular lymphoma, } \\
\text { CLL, severe RA, GPA, } \\
\text { Pemphigus vulgaris }\end{array}$ & $\begin{array}{l}\text { MabThera } \\
\text { (Roche) } \\
\text { MabThera }\end{array}$ & $\begin{array}{l}2019 \\
2019\end{array}$ \\
\hline & Somatropin & Omnitrope & Sandoz & Austria & $\begin{array}{l}\text { GH deficiency in } \\
\text { adults and children }\end{array}$ & $\begin{array}{l}\text { Genotropin } \\
\text { (Pfizer) }\end{array}$ & 2014 \\
\hline & $\begin{array}{l}\text { Trastuzumab } \\
\text { (2) }\end{array}$ & $\begin{array}{l}\text { Hertraz } \\
\text { Herzuma }\end{array}$ & $\begin{array}{l}\text { Biocon } \\
\text { Celltrion Inc/ } \\
\text { الحكرة }\end{array}$ & $\begin{array}{l}\text { India } \\
\text { Korea/Jordan }\end{array}$ & $\begin{array}{l}\text { BC, GC } \\
\text { Anticancer } \\
\text { monoclonal antibody }\end{array}$ & $\begin{array}{l}\text { Herceptin } \\
\text { Herceptin }\end{array}$ & $\begin{array}{l}2019 \\
2019\end{array}$ \\
\hline \multirow{3}{*}{$\begin{array}{l}\text { Malaysia } \\
(16)\end{array}$} & Bevacizumab & Mvasi & Amgen & USA & $\begin{array}{l}\mathrm{mCRC}, \mathrm{mBC} \text {, } \\
\text { Advanced, metastatic } \\
\text { or recurrent NSCLC, } \\
\text { Advanced and/or } \\
\text { mRCC, Glioblastoma, } \\
\text { EOC, FTC, pPC, CC }\end{array}$ & $\begin{array}{l}\text { Avastin } \\
\text { (Roche) }\end{array}$ & Jul 2019 \\
\hline & Epoetin Zeta & EPO Stada & InnoBio & $\begin{array}{l}\text { STADA Arz- } \\
\text { neimittel AG } \\
\text { (Germany) }\end{array}$ & $\begin{array}{l}\text { Anaemia with } \mathrm{CRF} \text {, } \\
\text { severe anaemic of } \\
\text { renal origin }\end{array}$ & \begin{tabular}{|l} 
Eprex \\
(Johnson \& \\
Johnson) \\
\end{tabular} & Oct 2015 \\
\hline & Filgrastim (2) & $\begin{array}{l}\text { Nivestim } \\
\text { Zarzio }\end{array}$ & $\begin{array}{l}\text { Hospira } \\
\text { Novartis }\end{array}$ & $\begin{array}{l}\text { IDT } \\
\text { Germany }\end{array}$ & $\begin{array}{l}\text { Chemotherapy-induced } \\
\text { febrile neutropenia, } \\
\text { PBPC, Persistent neu- } \\
\text { tropenia (ANC less than } \\
\text { or equal to } 1.0 \times 10_{\gamma} / \text { ) in } \\
\text { advanced HIV patients }\end{array}$ & $\begin{array}{l}\text { Neupogen } \\
\text { (Amgen-current } \\
\text { Roche-previous) } \\
\text { Neupogen } \\
\text { (Roche) }\end{array}$ & Mar 2012 \\
\hline
\end{tabular}


Table 1: Similar biotherapeutic products/biosimilars approved in 16 countries (continued)

\begin{tabular}{|c|c|c|c|c|c|c|c|}
\hline Country & INN & $\begin{array}{l}\text { Brand name } \\
\text { (product-specific } \\
\text { addition, e.g. } \\
\text { suffix, if any) }\end{array}$ & $\begin{array}{l}\text { Manufacturer/ } \\
\text { company name }\end{array}$ & $\begin{array}{l}\text { Origin of } \\
\text { country }\end{array}$ & Indications & $\begin{array}{l}\text { Reference } \\
\text { product } \\
\text { (manufacturer) }\end{array}$ & $\begin{array}{l}\text { Date } \\
\text { approved }\end{array}$ \\
\hline \multirow[t]{7}{*}{$\begin{array}{l}\text { Malaysia } \\
(16)\end{array}$} & Pegfilgrastim & Pelgraz & $\begin{array}{l}\text { Intas Pharma- } \\
\text { ceuticals Ltd, } \\
\text { Biopharma } \\
\text { Division (India)/ } \\
\text { Accord Health- } \\
\text { care Sdn Bhd }\end{array}$ & India & $\begin{array}{l}\text { Neutropenia, Chemo- } \\
\text { therapy-induced } \\
\text { febrile neutropenia } \\
\text { (with the exception } \\
\text { of chronic myeloid } \\
\text { leukaemia and myelo- } \\
\text { dysplastic syndromes) }\end{array}$ & Neulastim & Jul 2020 \\
\hline & Infliximab & Remsima & Celltrion & South Korea & $\mathrm{AS}, \mathrm{CD}, \mathrm{PsO}, \mathrm{RA}, \mathrm{UC}$ & \begin{tabular}{|l} 
Remicade \\
(Johnson \& \\
Johnson)
\end{tabular} & Jan 2015 \\
\hline & Rituximab & Truxima & Celltrion & South Korea & $\begin{array}{l}\text { NHL, CLL, RA with } \\
\text { GPA and MPA } \\
\text { *Initially these indica- } \\
\text { tions are approved but } \\
\text { the company intent to } \\
\text { remove due to local } \\
\text { patent issue }\end{array}$ & $\begin{array}{l}\text { MabThera } \\
\text { (Roche) }\end{array}$ & Aug 2018 \\
\hline & Somatropin & Scitropin A & United Italian & $\begin{array}{l}\text { Sandoz } \\
\text { Austria }\end{array}$ & $\begin{array}{l}\text { In children: Growth } \\
\text { disturbance due to GH } \\
\text { deficiency, associated } \\
\text { with Turner syndrome, } \\
\text { associated with chronic } \\
\text { renal insufficiency, or } \\
\text { in short children/ } \\
\text { adolescents born } \\
\text { small; PWS } \\
\text { In adults: GH } \\
\text { deficiency }\end{array}$ & $\begin{array}{l}\text { Genotropin } \\
\text { (Pfizer) }\end{array}$ & Aug 2010 \\
\hline & $\begin{array}{l}\text { Trastuzumab } \\
\text { (3) }\end{array}$ & Zuhera & Biocon & India & $\begin{array}{l}\text { HER2+ BC (m, early), } \\
\text { Advanced GC }\end{array}$ & $\begin{array}{l}\text { Herceptin } \\
\text { (Roche) }\end{array}$ & Dec 2018 \\
\hline & & Hertraz & Duopharma & India & Early BC, mBC, mGC & $\begin{array}{l}\text { Herceptin } \\
\text { (Roche) }\end{array}$ & Oct 2018 \\
\hline & & Herzuma & Celltrion & South Korea & Early BC, mBC, mGC & $\begin{array}{l}\text { Herceptin } \\
\text { (Roche) }\end{array}$ & May 2019 \\
\hline \multirow[t]{3}{*}{\begin{tabular}{|l|} 
Republic of \\
Korea (15)
\end{tabular}} & Adalimumab & Hadlima & Samsung Bio & South Korea & $\begin{array}{l}\text { PsO, PsA, JIA, RA, UC, } \\
\text { Adult CD, AS }\end{array}$ & \begin{tabular}{|l} 
Humira \\
(AbbVie)
\end{tabular} & Sep 2017 \\
\hline & $\begin{array}{l}\text { Darbepoetin } \\
\text { alfa }\end{array}$ & Nesbell & $\begin{array}{l}\text { Chongkun- } \\
\text { dang }\end{array}$ & South Korea & $\begin{array}{l}\text { Treatment of } \\
\text { anaemia }\end{array}$ & $\begin{array}{l}\text { Nesp Darb- } \\
\text { epoetin alfa }\end{array}$ & Nov 2018 \\
\hline & Epoetin alfa & Panpotin & $\begin{array}{l}\text { Pangen } \\
\text { Biotech }\end{array}$ & South Korea & $\begin{array}{l}\text { Anemia associated } \\
\text { with chronic renal } \\
\text { failure }\end{array}$ & \begin{tabular}{|l} 
Eprex \\
(Johnson \& \\
Johnson)
\end{tabular} & Nov 2019 \\
\hline
\end{tabular}




\section{Table 1: Similar biotherapeutic products/biosimilars approved in 16 countries (continued)}

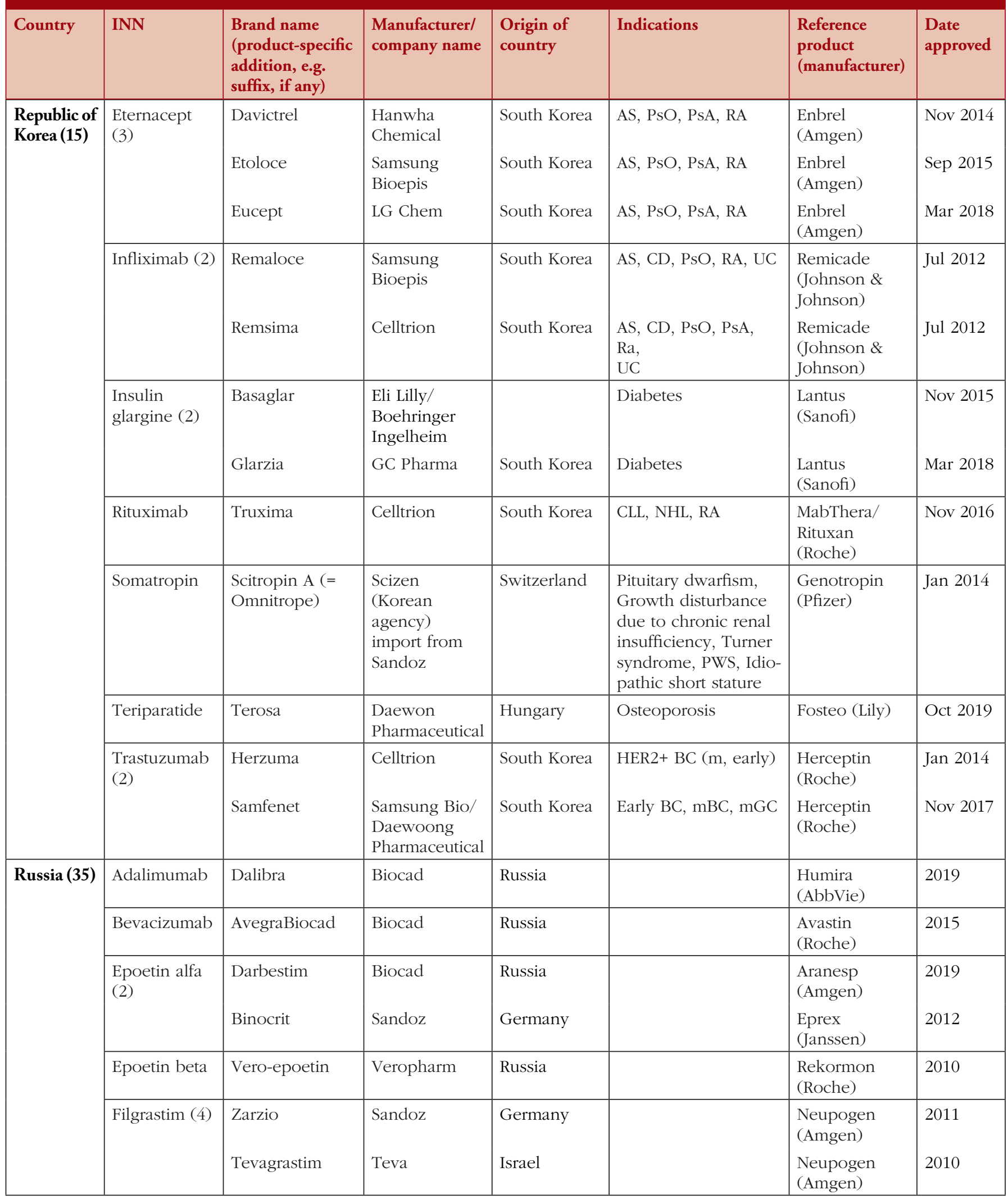




\section{Table 1: Similar biotherapeutic products/biosimilars approved in 16 countries (continued)}

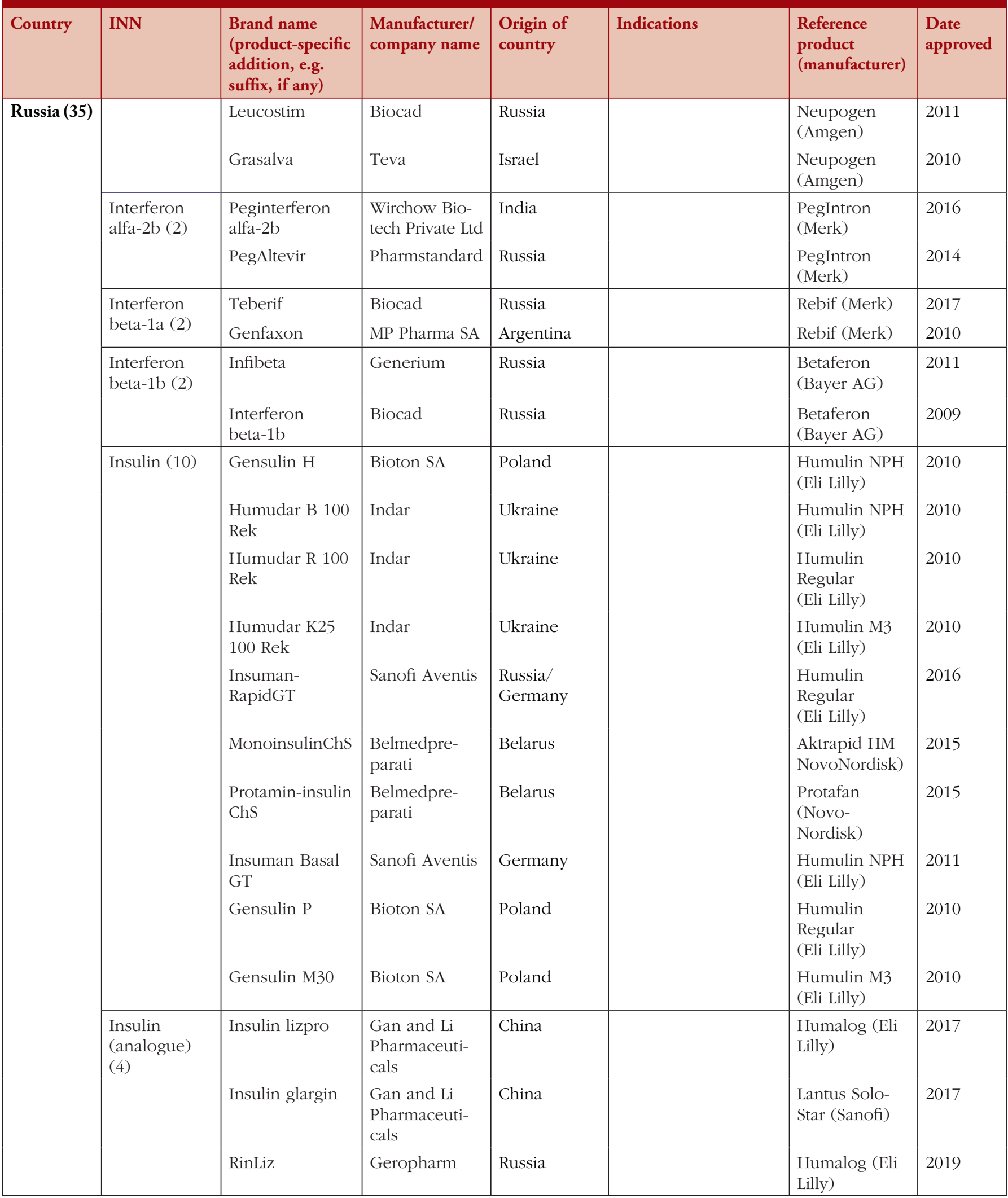




\section{Table 1: Similar biotherapeutic products/biosimilars approved in 16 countries (continued)}

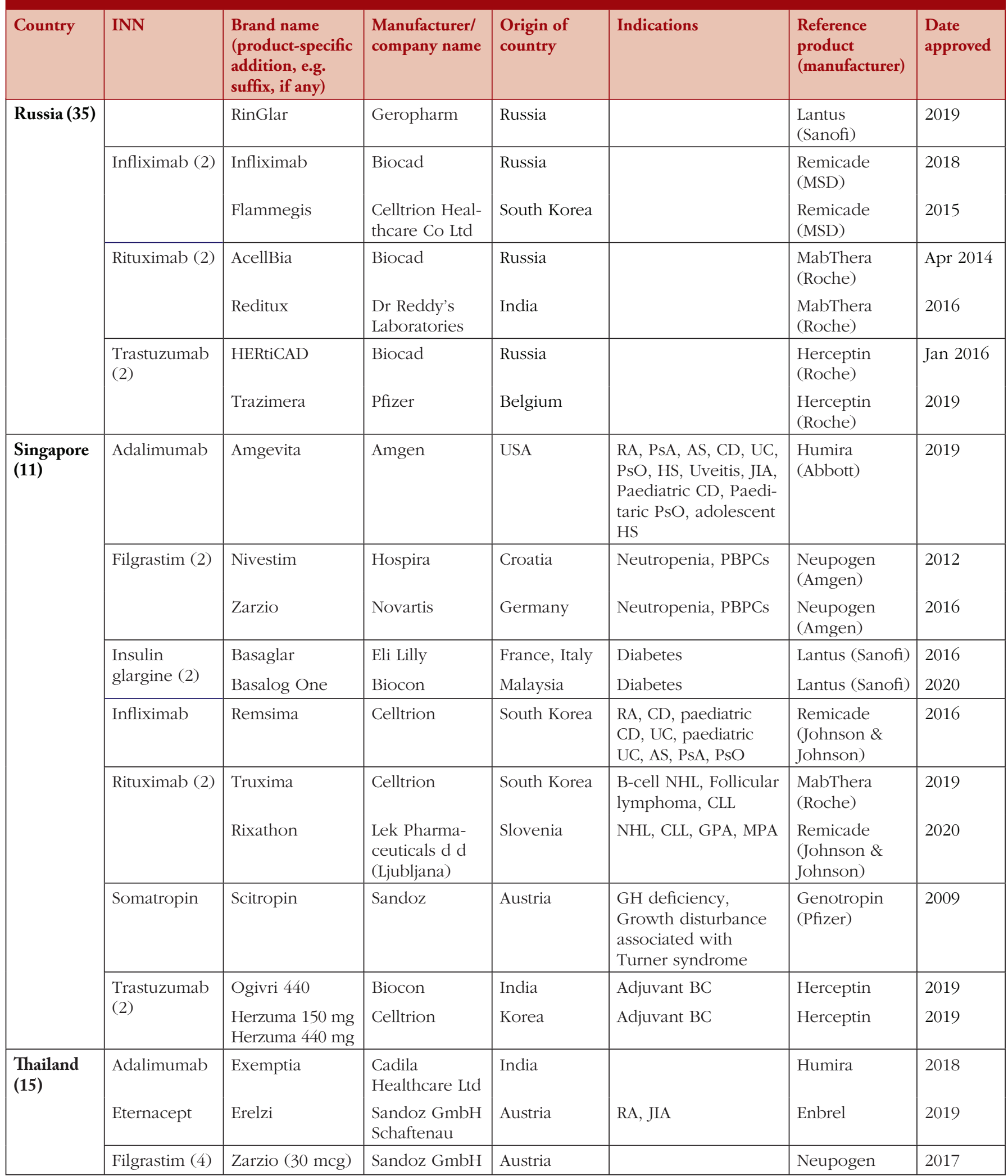




\section{Table 1: Similar biotherapeutic products/biosimilars approved in 16 countries (continued)}

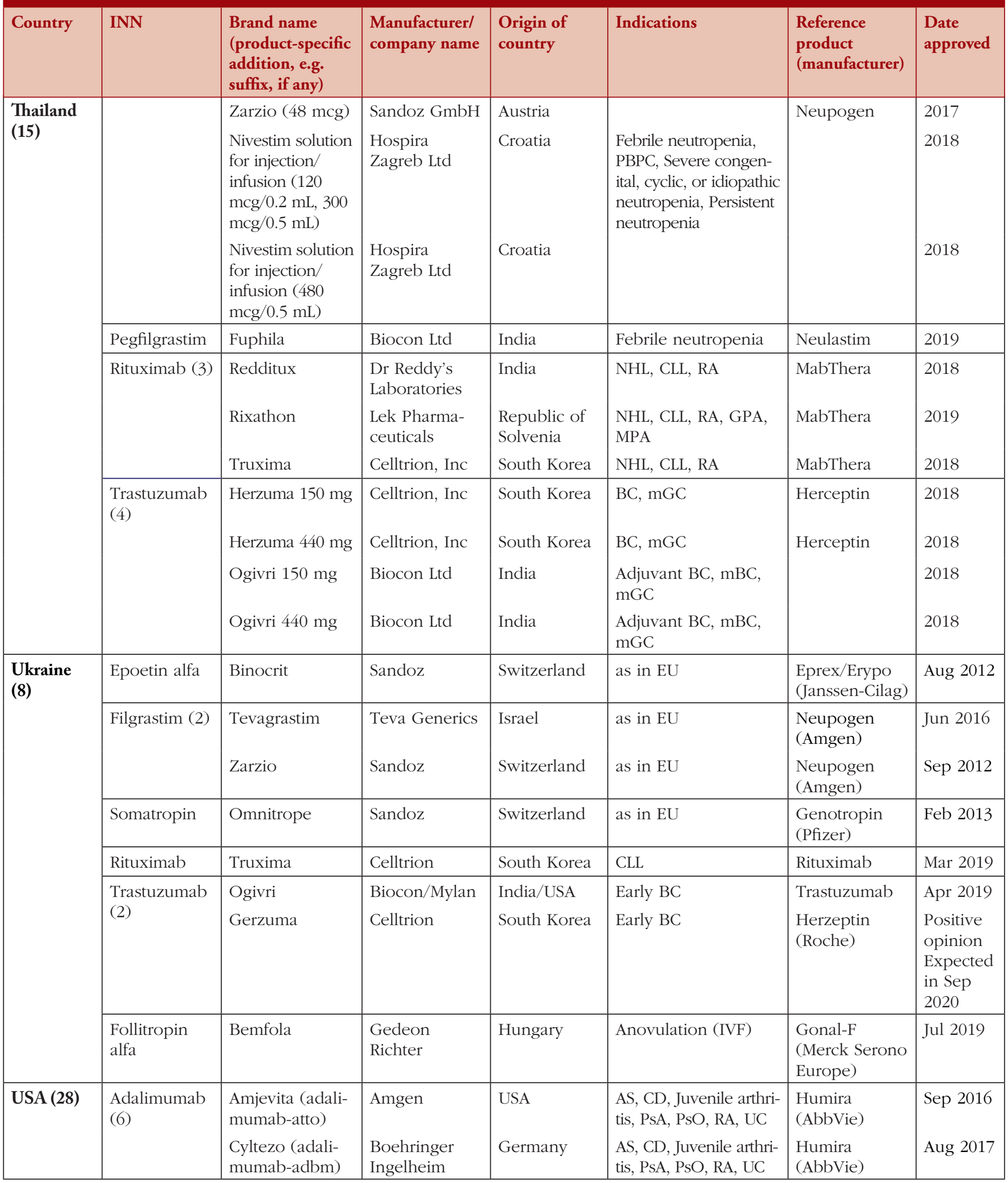




\section{Table 1: Similar biotherapeutic products/biosimilars approved in 16 countries (continued)}

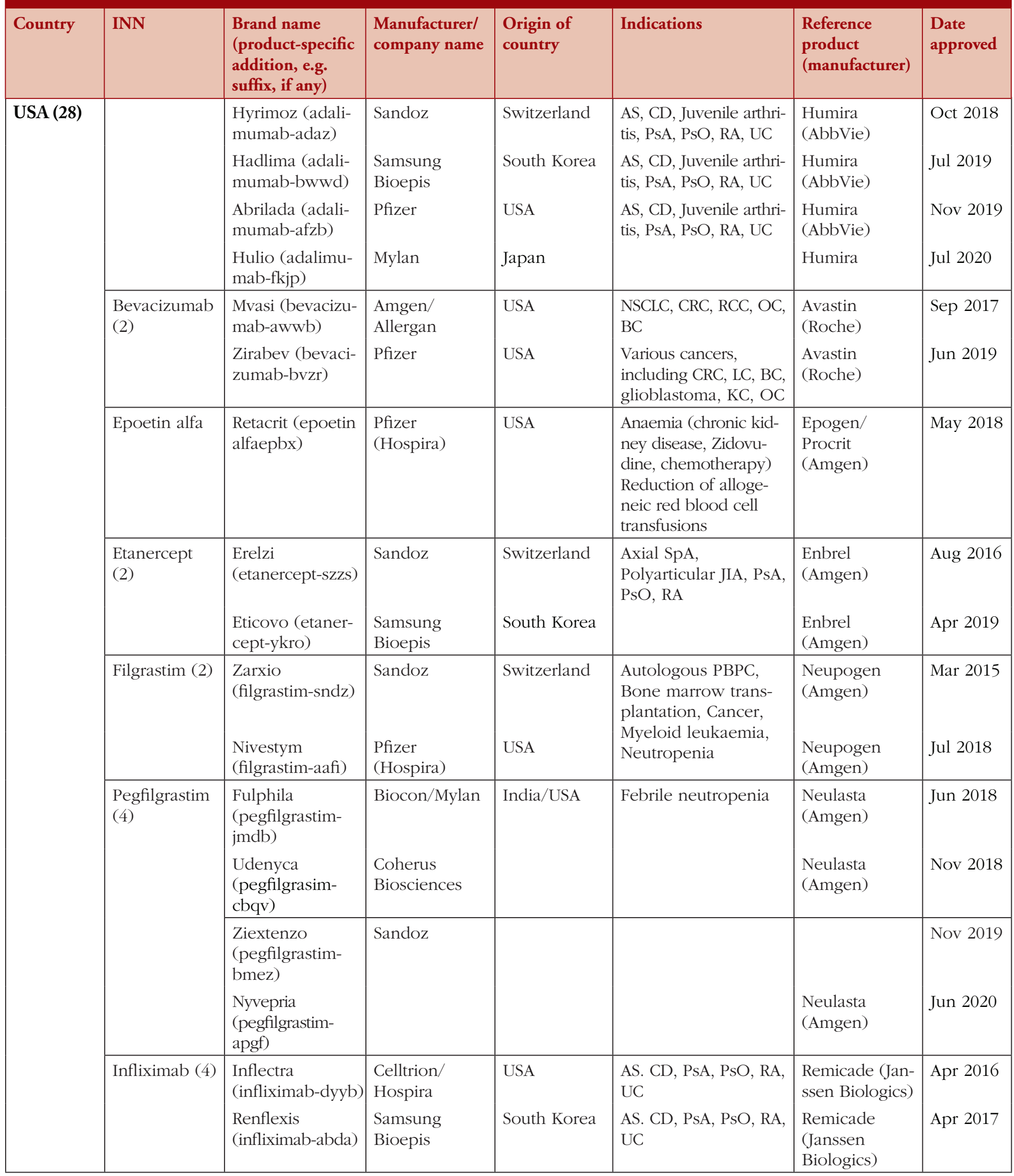


Table 1: Similar biotherapeutic products/biosimilars approved in 16 countries (continued)

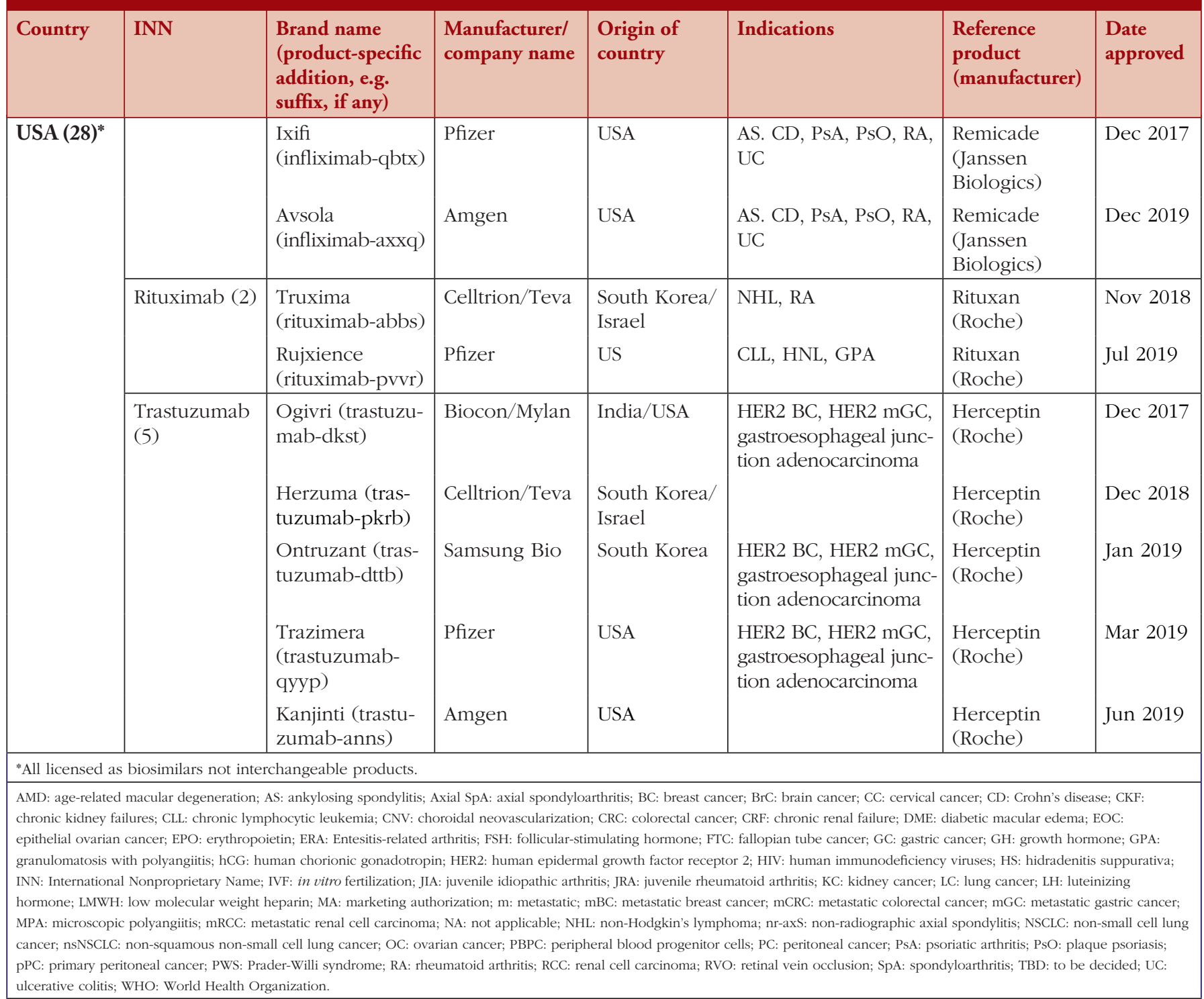

When compared with the situation in August 2019 [1], the major biosimilar products being approved as of July 2020 are monoclonal antibodies. For example, six and seven monoclonal antibody similar biotherapeutic products/biosimilars have been approved in Brazil and in Canada, respectively, during the updating period.

The quality of similar biotherapeutic products/biosimilars approved in some countries is still an issue for concern. Some products in certain countries were approved prior to adoption of regulations or guidelines for biosimilar evaluation, see Table 1 . As mentioned above, EMA was the first agency to adopt the biosimilar concept in 2006, so products called 'biosimilars' approved before 2006 are unlikely to be biosimilars [1]. Regulators need to reassess such products to ensure whether they meet the current requirements and to identify the inappropriate labelling of noninnovator and copy-version products (approved when regulatory procedures were not well defined) as biosimilars [7-9].
It is clear that increasing numbers of biosimilars are now available in many countries and provide more options for treatments. In certain countries, the availability of various product classes has been expanded by approval of biosimilars for which product classes were not available on the market previously. This is important for relatively expensive products, e.g. monoclonal antibodies. It is expected that adoption of biosimilars will allow affordable health care and greater patient access to important medicinal products [1].

\section{Disclaimer}

The authors alone are responsible for the views expressed in this manuscript and they do not necessarily represent the views, decisions or policies of the institutions with which they are affiliated. The survey participants are listed in alphabetical order in the author section after the three primary authors. 


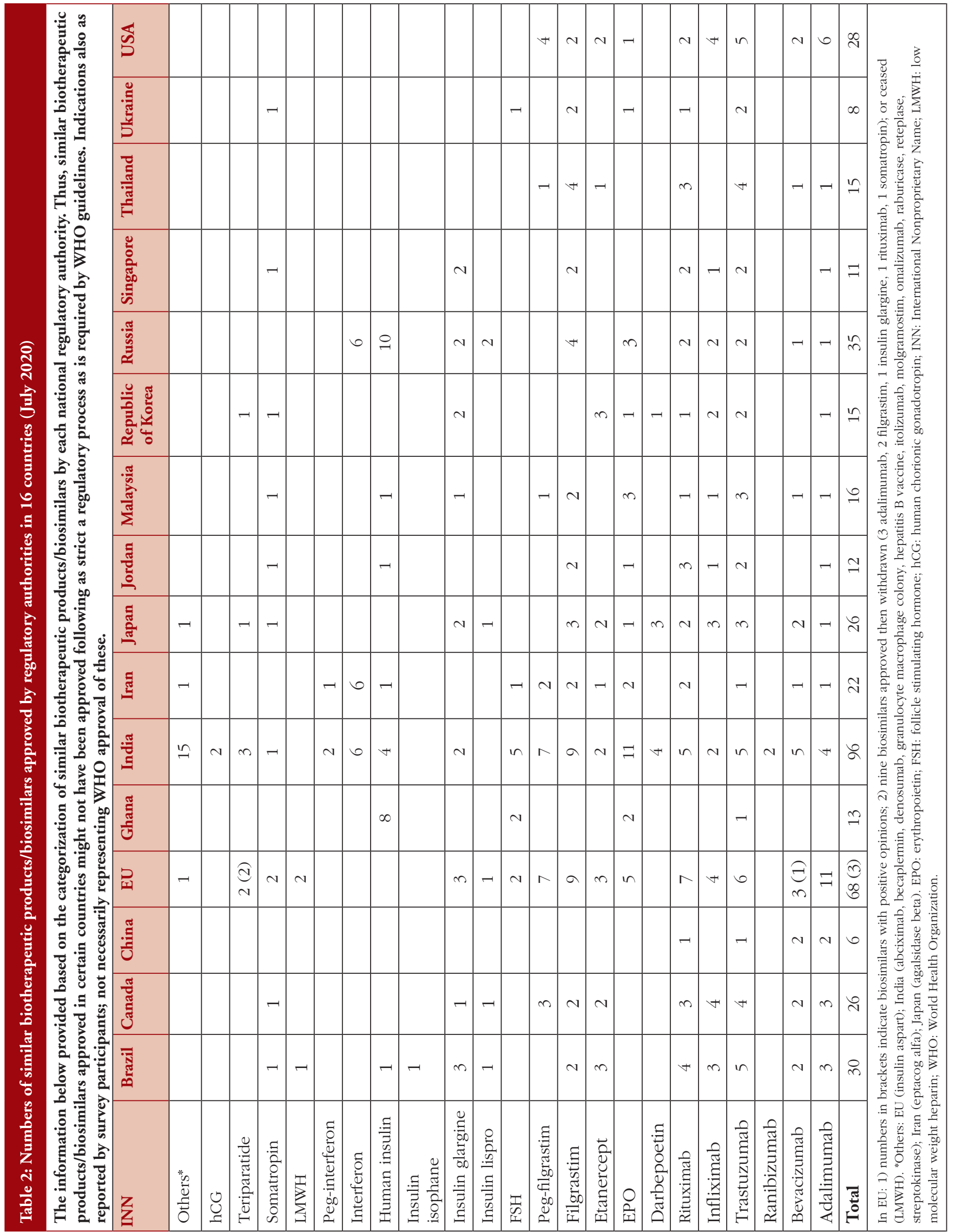


The information in this manuscript provided based on the categorization of biosimilars by each national regulatory authority. Thus, biosimilars approved in certain countries might not have been approved following as strict a regulatory process as is required by WHO guidelines. Indications in Table 1 also

\begin{tabular}{|c|c|}
\hline \multicolumn{2}{|c|}{ Acronyms and abbreviations } \\
\hline AMD & age-related macular degeneration \\
\hline AS & ankylosing spondylitis \\
\hline BC & breast cancer \\
\hline $\mathrm{BrC}$ & brain cancer \\
\hline CC & cervical cancer \\
\hline $\mathrm{CD}$ & Crohn's disease \\
\hline CKF & chronic kidney failure \\
\hline CLL & chronic lymphocytic leukaemia \\
\hline $\mathrm{CNV}$ & choroidal neovascularization \\
\hline CRC & colorectal cancer \\
\hline CRF & chronic renal failure \\
\hline DME & diabetic macular edema \\
\hline EMA & European Medicines Agency \\
\hline EOC & epithelial ovarian cancer \\
\hline EPO & erythropoietin \\
\hline ERA & entesitis-related arthritis \\
\hline FSH & follicle stimulating hormone \\
\hline FTC & fallopian tube cancer \\
\hline GC & gastric cancer \\
\hline GH & growth hormone \\
\hline GPA & granulomatosis with polyangiitis \\
\hline hCG & human chorionic gonadotropin \\
\hline HS & hidradenitis suppurativa \\
\hline INN & International Nonproprietary Name \\
\hline IVF & in vitro fertilization \\
\hline JIA & juvenile idiopathic arthritis \\
\hline JRA & juvenile rheumatoid arthritis \\
\hline $\mathrm{KC}$ & kidney cancer \\
\hline LC & lung cancer \\
\hline $\mathrm{LH}$ & luteinizing hormone \\
\hline LMWH & low molecular weight heparin \\
\hline $\mathrm{m}$ & metastatic \\
\hline MA & marketing authorization \\
\hline MPA & Microscopic Polyangiitis \\
\hline NHL & Non-Hodgkin lymphoma \\
\hline nr-axS & Non-radiographic axial spondylitis \\
\hline nSNSCLC & Non-squamous non-small cell lung cancer \\
\hline OC & Ovarian cancer \\
\hline $\mathrm{p}$ & primary \\
\hline PBPC & peripheral blood progenitor cells \\
\hline PC & peritoneal cancer \\
\hline PsA & psoriatic arthritis \\
\hline PsO & plaque psoriasis \\
\hline PWS & Prader-Willi syndrome \\
\hline RA & rheumatoid arthritis/ \\
\hline RCC & renal cell carcinoma \\
\hline RVO & retinal vein occlusion \\
\hline SpA & spondyloarthritis \\
\hline UC & ulcerative colitis \\
\hline
\end{tabular}

as reported by survey participants; not necessarily representing WHO approval of these.

The World Health Organization retains copyright and all other rights (CC BY 3.0 IGO) in the manuscript of this article as submitted for publication.

\section{Funding sources}

The Ministry of Health and Welfare of Republic of Korea provided the fund to WHO for this project through a voluntary contribution for the period of 1 December 2018-30 September 2021.

Competing interests: The authors have disclosed no potential conflicts of interests.

Provenance and peer review: Not commissioned; externally peer reviewed.

\section{Authors}

Hye-Na Kang ${ }^{1}$, PhD

Robin Thorpe ${ }^{2}$ PhD

Ivana Knezevic ${ }^{1}, \mathrm{PhD}$

Daehyun $\mathrm{Baek}^{3}$, PhD

Parichard Chirachanakul ${ }^{4}$

Hui Ming Chua 5

Dina Dalili ${ }^{6}, \mathrm{PhD}$

Freddie $\mathrm{FOO}^{7}$, MSC

Kai $\mathrm{GaO}^{8}, \mathrm{PhD}$

Suna Habahbeh', PhD

Hugo Hamel ${ }^{10}$, PhD

Edwin Nkansah" ${ }^{11}, \mathrm{PhD}$

Maria Savkina ${ }^{12}, \mathrm{PhD}$

Oleh Semeniuk ${ }^{13}$

Shraddha Srivastava ${ }^{14}$

João Tavares Neto ${ }^{15}$, PhD

Meenu Wadhwa ${ }^{16}$, PhD

Teruhide Yamaguchi ${ }^{17}$, PhD

${ }^{1}$ World Health Organization, Department of Health Product Policy and Standards, 20 Avenue Appia, CH-1211 Geneva, Switzerland ${ }^{2}$ Independent expert, Welwyn, UK

${ }^{3}$ Ministry of Food and Drug Safety, Osong, Republic of Korea

${ }^{4}$ Food and Drug Administration, Nonthaburi, Thailand

${ }^{5}$ National Pharmaceutical Regulatory Agency, Selangor, Malaysia

${ }^{6}$ Iran Food and Drug Administration, Tehran, Iran

${ }^{7}$ Health Sciences Authority, Singapore

${ }^{8}$ Shanghai University, Shanghai, People's Republic of China ${ }^{9}$ Jordan Food and Drug Administration, Amman, Jordan

${ }^{10}$ Health Canada, Ottawa, Canada

${ }^{11}$ Food and Drugs Authority, Accra, Ghana

${ }^{12}$ Centre for Evaluation and Control of Medicinal Immunobiological Products of the FSBI "SCEEMP" of the Ministry of Health of Russia, Moscow, Russian Federation

${ }^{13}$ Ministry of Health of Ukraine, Kyiv, Ukraine

${ }^{14}$ Central Drug Standards Control Organization (CDSCO), Ministry of Health \& Family Welfare, New Delhi, India

${ }^{15}$ Brazilian Health Regulatory Agency (ANVISA), Brasilia, Brazil

${ }^{16}$ National Institute for Biological Standards and Control, Medicines and Healthcare products Regulatory Agency, Potters Bar, UK

${ }^{17}$ Pharmaceuticals and Medical Devices Agency, Tokyo, Japan 


\section{References}

1. Kang H-N, Thorpe R, Knezevic I, Survey participants from 19 countries. The regulatory landscape of biosimilars: WHO efforts and progress made from 2009 to 2019. Biologicals. 2020;65:1-9.

2. WHO Expert Committee on Biological Standardization. 2013. Annex 2. Guidelines on evaluation of similar biotherapeutic products (SBPs). WHO Technical Report Series no. 977 [homepage on the Internet]. [cited 2020 Nov 25]. Available from: http://who.int/biologicals/publications/trs/areas/biological_therapeutics/TRS_977_Annex_2.pdf

3. World Health Organization. WHO Questions and Answers: similar biotherapeutic products. 2018 [homepage on the Internet]. [cited 2020 Nov 25]. Available from: https://www.who.int/biologicals/expert_committee/QA_for_ SBPs_ECBS_2018.pdf?ua=1

4. WHO Expert Committee on Biological Standardization. 2017. Annex 2. Guidelines on evaluation of monoclonal antibodies as similar biotherapeutic products (SBPs). WHO Technical Report Series no. 1004 [homepage on the Internet]. [cited 2020 Nov 25]. Available from: https://www.who.int/biologicals/biotherapeutics/WHO_TRS_1004_web_Annex_2.pdf?ua=1
5. Kang H-N. Summary of the diverse situation of similar biotherapeutic products in the selected countries (August 2010). Biologicals. 2011;39(5):304-7.

6. Kang H-N, Thorpe R, Knezevic I, Casa Levano M, Chilufya MB, Chirachanakul P, et al. 2020. Regulatory challenges with biosimilars: an update from 20 countries. Ann N Y Acad Sci. 2020 Nov 21. doi: 10.1111/nyas.14522. Online ahead of print.

7. Recommendations. 14th International Conference of Drug Regulatory Authorities (CDRA); 30 November-3 December 2010; Singapore.

8. Kang H-N, Knezevic I. Regulatory evaluation of biosimilars throughout their product life-cycle. Bull World Health Organ. 2018;96(4):281-5.

9. WHO Expert Committee on Biological Standardization. Annex 3. Regulatory assessment of approved rDNA-derived biotherapeutics. WHO Technical Report Series no. 999, 2016 [homepage on the Internet]. [cited 2020 Nov 25]. Available from: https://www.who.int/biologicals/areas/biological_therapeutics/Annex_3_Regulatory_assessment_of_approved_rDNA-derived_biotherapeutics.pdf?ua=1

DOI: 10.5639/gabij.2021.1001.002

Copyright (c) 2021 Pro Pharma Communications International 